\title{
Neuronal Migration During Development of the Cerebellum
}

\author{
Maryam Rahimi-Balaei ${ }^{1,2}$, Hugo Bergen ${ }^{1}$, Jiming Kong ${ }^{1}$ and Hassan Marzban ${ }^{1,2 *}$ \\ ${ }^{1}$ Department of Human Anatomy and Cell Science, Max Rady College of Medicine, Rady Faculty of Health Sciences, \\ University of Manitoba, Winnipeg, MB, Canada, ${ }^{2}$ The Children's Hospital Research Institute of Manitoba (CHRIM), Max Rady \\ College of Medicine, Rady Faculty of Health Sciences, University of Manitoba, Winnipeg, MB, Canada
}

\section{OPEN ACCESS}

Edited by:

Jing-Ning Zhu,

Nanjing University, China

Reviewed by:

Takaki Miyata,

Nagoya University, Japan

Salvador Martinez,

Universidad Miguel Hernández de

Elche, Spain

Roy Vincent Sillitoe,

Baylor College of Medicine,

United States

*Correspondence:

Hassan Marzban

hassan.marzban@umanitoba.ca

Received: 06 July 2018 Accepted: 27 November 2018 Published: 17 December 2018

Citation:

Rahimi-Balaei M, Bergen H, Kong J and Marzban H (2018) Neuronal Migration During Development of the

Cerebellum.

Front. Cell. Neurosci. 12:484. doi: 10.3389/fncel.2018.00484
Neuronal migration is a fundamental process in central nervous system (CNS) development. The assembly of functioning neuronal circuits relies on neuronal migration occurring in the appropriate spatio-temporal pattern. A defect in the neuronal migration may result in a neurological disorder. The cerebellum, as a part of the CNS, plays a pivotal role in motor coordination and non-motor functions such as emotion, cognition and language. The excitatory and inhibitory neurons within the cerebellum originate from different distinct germinal zones and migrate through complex routes to assemble in a well-defined neuronal organization in the cerebellar cortex and nuclei. In this review article, the neuronal migration modes and pathways from germinal zones to the final position in the cerebellar cortex and nuclei will be described. The cellular and molecular mechanisms involved in cerebellar neuronal migration during development will also be reviewed. Finally, some diseases and animal models associated with defects in neuronal migration will be presented.

Keywords: neuron, migration, cerebellum, development, mechanism

\section{INTRODUCTION}

The structural and functional development of the central nervous system (CNS) depends on neurogenesis, neuronal migration and circuit formation. This is a complex sequence of events involving a variety of molecular pathways. Neuronal migration is an essential phenomenon for normal development as it brings cells into appropriate spatial relationships with other cells

\footnotetext{
Abbreviations: Acp2, lysosomal acid phosphatase 2; ApoER2, apolipoprotein E receptor 2; Astn, astrotactin 1; Atoh1, atonal homolog 1; BDNF, brain-derived neurotrophic factor; CAMs, cell adhesion molecules; CN, cerebellar nuclei; CNN, cerebellar nuclei neuron; CNS, central nervous system; CXCL12, chemokine ligand 12; CXCR4, chemokine receptor 4; Dab1, disabled-1; DCC, deleted in colorectal cancer; DCX, doublecortin; E, embryonic day; EAAT1, excitatory amino acid transporter; EGF, epidermal growth factor; ErbB4, Erb-B2 receptor tyrosine kinase 4; FoxP2, forkhead box protein P2; GABA, gamma amino butyric acid; GC, granule cell; GCP, granule cell precursor; GFAP, glial fibrillary acidic protein; GLASTs, glutamate receptors and transporters; HGF/SF, hepatocyte growth factor/scatter factor; i, isthmus; IN, interneuron; IZ, intermediate zone; KCC2, potassium-chloride co-transporter; LIS1, lissencephaly-1 homolog; Lmx1a, LIM homeobox transcription factor 1 alpha; m, mesencephalon; MAP, microtubule-associated protein; MDM2, mouse double minute 2 homolog; MZ, marginal zone; Nfl, neurofibromatosis type 1; NRG1, neuregulin-1; NTZ, nuclear transitory zone; P, postnatal day; Pax2, paired homeobox gene 2; Pax6, paired homeobox gene 6; PC, purkinje cell; PCC, purkinje cell cluster; PCP, purkinje cell plate; Pex2, peroxisomal biogenesis factor 2; Ptfla, pancreas specific transcription factor 1a; RL, rhombic lip; Rp58, 58 KDa repressor protein; SDF-1, stromal derived factor 1; Sema3A, semaphorin 3a; Sema6A, semaphorin 6A; Shh, sonic hedgehog; SmoA2, smoothened A2; SVZ, subventricular zone; Tbr1, T-box, brain, 1; Tbr2, T-box, brain, 2; UBC, unipolar brush cells; uPAR, urokinase-type plasminogen activator receptor; VLDLR, very-low-density lipoprotein receptor; VPS18, vacuole protein sorting 18; VZ, ventricular zone.
} 
(Marín et al., 2010). During development, newborn neurons form within the neuroepithelium, a proliferative layer of the neural tube. Under tightly controlled conditions, the newborn neurons migrate from their germinal zone and disperse throughout the CNS to reach their final destination where they subsequently become part of an appropriate lamination and neuronal circuit (Cooper, 2013). Cell polarity is required for neuronal migration which is dependent on cytoskeletal changes in concert with cell adhesion receptor systems that are regulated by a wide variety of molecules (Govek et al., 2011). Neuronal locomotion can be divided to three phases: (1) extension of the leading process; (2) nucleokinesis; and (3) retraction of the trailing process (Tsai and Gleeson, 2005). The main mode of neuronal migration is somal translocation which uses extracellular matrix components (Nadarajah and Parnavelas, 2002), glial fibers (Hatten, 1990), blood vessels (Tsai et al., 2016), axons (Takei et al., 2000) and possibly pia mater (Komuro and Yacubova, 2003) as substrates. Neuronal migration follows either a radial or a tangential migratory pathway, depending on the area of the developing nervous system in which the neurons originate. In radial migration, nascent neurons follow a track that is perpendicular to the neuroepithelial surface and the neurons proceed alongside radial glial fibers (Marín and Rubenstein, 2001). In contrast, the tangential migration of neurons is parallel to the pial surface (Nadarajah et al., 2001). There is also a dual phase neuronal migration referred to as a switching migration, which is a combination of tangential and radial migration (Kawaji et al., 2004).

In this article, the neuronal migration modes and the direction and pathways from origin to the final position during CNS development will be reviewed. Then, we will review the migration of cerebellar neurons with an emphasis on Purkinje cells (PCs). Finally, we will describe some diseases and animal models associated with defects in neuronal migration.

\section{THE CELLULAR AND MOLECULAR MECHANISMS INVOLVED IN NEURONAL MIGRATION}

During neuronal migration, neuronal precursor cells move forward, switch their direction, or change their migration mode to reach their final position, which is fundamental for nervous system function. All of these processes are under an elaborate control system and have been studied extensively (Table 1). In this section, we will describe the main molecular and cellular mechanisms involved in neuronal migration during CNS development and then the migration of each cerebellar neuronal type will be described.

Migrating neurons exhibit highly polarized cell morphology in the direction of their movement. The polarized neurons are defined as having a leading process and a trailing process. The leading process is a structure that is similar to the growth cones of growing axons, whereas the trailing process is a short process at the posterior part of the cell. The formation of these processes is regulated by precise cellular and molecular mechanisms through which extrinsic and intrinsic signaling
TABLE 1 | Methods to study neuronal migration (Mannan et al., 2004; Baubet et al., 2012; Rahimi-Balaei et al., 2016).

\begin{tabular}{ll}
\hline Techniques for progenitor differentiation and neuronal migration \\
\hline Traditional & a) Analysis of fixed tissue \\
b) in vitro: culture of individual cells \\
a) Electron microscopy \\
b) Autoradiography \\
c) Tissue culture methods \\
d) Chimeras \\
e) X-ray crystallography \\
f) Genetic labeling \\
a) Live imaging techniques \\
b) Genetic labeling of distinct cell types in developing brain \\
c) In vitro migration assay using dissociated neuronal cells \\
migration (boyden chamber assays and gap closure assays) \\
d) Real-time neuronal migration in embryonic brain slice assay \\
(fluorescent dyes or XFP transgenes, lipophilic or vital dyes, \\
such as Dil, DiO, CMTMR, Oregon Green plus dye- or \\
transgene-coated gold particles in utero or ex vivo \\
electroporation) \\
e) Neuronal migration in embryonic brain explants in 3-D matrigel \\
f) Embryonic culture \\
g) Dynamic in-silico model for neuronal migration
\end{tabular}

pathways change the cytoskeleton resulting in pulling and pushing forces (Matsuki et al., 2013; Nguyen and Hippenmeyer, 2013). The major structures that define the leading edge activity of migrating neurons are lamellipodia and filopodia (Kurosaka and Kashina, 2008). Initially a lamellipodium-like network forms and then filopodia form through the addition of monomers to filaments and assembly with adjacent filaments (Davies, 2013). Lamellipodia are broad membrane protrusions at the leading edge of cells that arise as a result of actin polymerization. Lamellipodia are dynamic structures that include protrusion and retraction activities (Krause and Gautreau, 2014). On the other hand, filopodia are thin protrusions of the lamellipodium plasma-membrane. The formation of filopodia is a highly dynamic process and these structures function as antennae to navigate and direct cell migration. The initiation and elongation of filopodia depends on the precise regulation of polymerization, crosslinking and assembly by various actin-associated proteins (Mattila and Lappalainen, 2008).

The movements of neurons are controlled by the generation, maintenance and remodeling of a leading process. The leading process of the neuron marks the direction of neuronal migration, followed by movement of the cell somata (somal translocation) along with the translocation of the nucleus (nucleokinesis), and finally the migrating neuron eliminates its trailing process. Leading processes interact with the surrounding microenvironment to guide neuronal movements (Nguyen and Hippenmeyer, 2013). The remodeling of the leading process will repeatedly initiate new migratory cycles until it reaches its final destination (Nguyen and Hippenmeyer, 2013). Cytoskeletal proteins such as microtubules, actin and actomyosin play important roles in nucleokinesis and cell locomotion. The centrosome is the main microtubule organizing center and as it moves forward, it pulls forward the longitudinal array of microtubules in association with the Golgi apparatus, which is followed by the movement of the nucleus. The absence of microtubules at the trailing part of the cell may initiate 
contractions dependent on myosin II, and this pushing force on the nucleus results in moving forward and breaks adhesions at the trailing part of the cell. The role of actomyosin contraction at the back part of the cell also plays an important role in the migration of cortical interneurons (INs; Martini and Valdeolmillos, 2010). The somal translocation process is the main mode of neuronal migration during the early stage of embryonic development and includes the radially migrating neurons such as cerebellar granule cells (GCs) that move along the Bergmann glia fibers. A wide range of cellular events, including cell adhesion, modulate this migration (Hatten, 1999; Nadarajah et al., 2001; Sanada et al., 2004).

It has been shown that Lissencephaly-1 homolog, (LIS1, a member of the microtubule-associated proteins, MAPs) and doublecortin (DCX, a member of MAP that directly polymerizes purified tubulin into microtubules) are important in the translocation of the neuronal cell body during neuronal migration. Both molecules are components of an evolutionarily conserved pathway regulating microtubule function and cell migration (Gleeson et al., 1999; Feng and Walsh, 2001). In addition, the microtubule bundling that is accompanied by the action of dynein mediates coupling of the nucleus to the centrosome (modulating and stabilizing microtubules; Tanaka et al., 2004). In another study, it has been shown that LIS1 and dynein play a role in radial neuronal migration (Wynshaw-Boris and Gambello, 2001). In males, DCX mutations produce lissencephaly phenotypes similar to those associated with LIS1 mutations (Gleeson et al., 1998). Recently, c-Jun $\mathrm{N}$-terminal signaling pathway has gained attention as one of the critical regulators of neuronal mobility. Indeed, components of this pathway activate some specific brain proteins (e.g., by phosphorylation of the MAP1B and MAP2) which affect the stability of microtubules in neurons and neuronal migration (Tsai et al., 2016). In cerebellar GC migration, that is assisted by Bergmann glia, the majority of F-actin and myosin II is located at the front of the nucleus rather than the trailing end, suggesting these proteins may pull the soma forward (Solecki et al., 2009).

In addition to intrinsic factors discussed above, there are several extrinsic factors (also known as motogens) involved in neuronal migration. Gamma amino butyric acid (GABA) secreted by neurons themselves, acts as an extrinsic factor and accelerates their migration. In mice deficient in GABA, the migration rate of neurons is decreased, which is consistent with a role for GABA as a motogen (Inada et al., 2011). Hepatocyte growth factor/scatter factor (HGF/SF) is another extrinsic factor involved in migration. In mice lacking the urokinase-type plasminogen activator receptor (uPAR, a key component of HGF/SF activation), neurons exhibit abnormal migration from the ganglionic eminence, which leads to a reduced number of neurons in the frontal and parietal cortices (Powell et al., 2001).

The rate of cerebellar GC migration is controlled positively through the frequency of the intracellular calcium fluctuation and negatively regulates the rate of the extension of axonal growth cones. In cortical migratory interneurons, their motility is stimulated by the activation of GABA and glutamate receptors. An up-regulation of the potassium-chloride co-transporter
(KCC2) plays a key role in reducing interneuron motility through its ability to reduce membrane potential upon gammaaminobutyric acid $\mathrm{A}\left(\mathrm{GABA}_{\mathrm{A}}\right)$ receptor activation, and decrease the frequency of intracellular calcium transients. Subsequently, during early postnatal weeks the expression of KCC2 is increased and early-born interneurons express higher levels of KCC2 compared to late-born interneurons (Bortone and Polleux, 2009).

The control of the specific direction of the migration in cortical neurons originating from the subventricular zone (SVZ) is a combination of the leading process and the use of scaffolds (such as the radial glia; Marín et al., 2010). However, there are additional factors such as semaphorin $3 \mathrm{~A}$ (Sema3A), which acts like an attractant and is expressed in descending gradients across cortical layers, that guide newborn cortical neurons to the upper cortical layers (Chen et al., 2008). During development of pontine nuclei in the hindbrain, neurons reach the midline and Netrin-1 acts as a midline attractant and these neurons themselves express deleted in colorectal cancer (DCC), a Netrin-1 receptor), to assist these neurons to reach the midline (Yee et al., 1999). Neuregulin-1 (NRG1) is a member of the NRG family of proteins that contains an epidermal growth factor (EGF)-like motif that activates EGF receptor. It is expressed in the developing cortex and acts as a chemoattractant. Erb-B2 Receptor Tyrosine Kinase 4 (ErbB4), the NRG1 receptor, is expressed in migrating interneurons (Flames et al., 2004).

It is clear that several intrinsic and extrinsic factors are involved in the regulating neuronal migration. The mode of the neuronal migration, its direction, and finally the positioning of the neurons, which is important for neuronal circuit formation and function, are regulated by a complex molecular pathway that is currently not fully understood and need to be addressed in future. In the next section, we discuss direction of neuronal migration. The orientation and directionality of cell migration can be classified into two basic axes (radial and tangential) that use different types of substrates such as glial processes or neuronal axons (Rakic, 1990).

\section{Radial Migration}

Radial migration occurs in two opposite directions: (1) pial-directed migration in which neurons migrate toward the pial surface (or the outer neural tube surface); and (2) radially inward migration in which neurons migrate away from the pial surface. In the pial-directed radial migration, the neural progenitors or neuroepithelial derived cells migrate from their site of origin toward the pial surface to reach the mantle zone. Radial glial cells, which express glial fibrillary acidic protein (GFAP), play an important role in promoting the generation of neuronal progenitors and providing the migratory substrate during the neuronal migration (Tabata and Nakajima, 2003). Although pyramidal cells of the cerebral cortex are the classical example of pial-directed radial migration, a recent study has demonstrated this movement is not as straight forward as previously thought. Recently, it has been described that neurons may switch the mode of their migratory pathway (in the intermediate and subventricular zone, IZ/SVZ) before starting radial migration (Tabata and Nakajima, 2003). 
During inward radial migration, neurons move away from the pial layer after their tangential migration. The typical examples for this mode of migration are cerebellar GCs and pontine nuclei neurons (Kawauchi et al., 2006).

\section{Tangential Migration}

Tangential migration occurs in two different manners: (1) directed; and (2) non-directed. In the directed manner of migration, many neurons and interneurons migrate tangentially from their site of origin toward a specific direction. This includes cerebellar granule cell precursors (GCPs), interneurons of the cerebral cortex, neurons of the pontine nuclei, Cajal Retzius cells, neurons of the lateral reticular nucleus, and neuronal migration from the telencephalon to the olfactory bulb. The interneurons of the cerebral cortex migrate between the pallium and subpallium and the neurons of the pontine nuclei migrate between rhombomeres (Nóbrega-Pereira and Marin, 2009). Cajal-Retzius cells play an important role during neuronal migration as they secrete Reelin to guide the radial migration of the projection neurons of the neocortex. These cells originate from the discrete pallium and by tangential migration they will colonize the surface of the entire cortex (Bielle et al., 2005; Gil-Sanz et al., 2013).

The non-directed manner of tangential migration is more complicated than other modes of the migration, in that some groups of neurons exhibit migrations in all directions of the tangential plane. For example, interneurons of the marginal zone (MZ) of the cerebral cortex migrate tangentially in different directions, or change their direction repeatedly, which is referred to as random walk (Tanaka et al., 2009).

\section{Switching Migration (Mode and Direction)}

Although many neurons migrate simply to reach their final destinations, for some neurons the migration is more complicated and involves a type of migration referred to as switching migration (random walk). Switching migration can occur dynamically and includes switching from radial to tangential migration or directed to non-directed manner, and vice versa. For example, tangentially migrating cerebellar GCPs in the external germinal zone place a leading and a trailing process oriented horizontally and then orient these processes vertically to the putative molecular layer from the cell body (Komuro and Yacubova, 2003). After a stationary period following the tangential migration, the GCs switch to radial migration and migrate to the direction of their descending processes (Komuro and Yacubova, 2003). Similarly, pontine nuclei neurons also switch their mode of migration from tangential to radial as they approach the region of the pontine nuclei. The leading processes of pontine nuclei neurons divert their direction radially and start radial migration. In some neurons of the pontine nuclei, the new-born process initially elongates radially and subsequently results in the radial migration of their soma (Hatten, 1990).

The basic mechanisms and principles of neuronal migration during development that are described above are general and similar for most of the neuronal types in the CNS. However, depending on the area of the developing CNS, diverse classes of neurons follow different strategies and may use distinct molecular cues and substrate during migration from their origin to their final position. Based on this, the following sections will focus on neuronal migration in the cerebellum.

\section{THE NEURONAL MIGRATION IN THE DEVELOPING CEREBELLUM}

Similar to the other regions of the brain, neuronal migration plays a substantial role in the development of cerebellar circuits (Hoshino et al., 2005). Relatively few cell types are aggregated to form the cerebellar gray matter, which includes the cerebellar cortex and the cerebellar nuclei $(\mathrm{CN})$. The neurons that reside within the cerebellum are derived from two distinct germinal zones: the VZ and the rostral rhombic lip (RL). The VZ is the neuroepithelium of the alar plate of rhombomere 1 that will form the roof of the 4 th ventricle. The neurons derived from the VZ includes PCs, Golgi cells, stellate cells and basket cells (Butts et al., 2014). All of these neurons are derived from neural progenitors that express pancreas specific transcription factor 1a (Ptf1a) and use GABA as a neurotransmitter (Hoshino et al., 2005). The cerebellar neurons derived from the RL at the dorsal edge of the cerebellar primordium, include the large neurons of the $\mathrm{CN}$ (which provide the output of the cerebellum), unipolar brush cells (UBCs), and the GCs (the most numerous cell in the brain; Elsen et al., 2013). All of these neurons originate from neuronal progenitors that express Atonal homolog 1 (Atoh1, formerly known as Math1) and use glutamate as their neurotransmitter (Manto et al., 2013).

The cerebellar cortex segregates into three layers: the molecular layer (stellate and basket cells), the PC layer (PCs and candelabrum cells) and the granular cell layer (GCs, Golgi cells, UBCs and Lugaro cells). The two most distinctive cells in the cerebellar cortex are the large PCs and the small GCs. PCs are the principal neurons of the cerebellar cortex, and the sole output of the cerebellar cortex projecting an axon to the $\mathrm{CN}$. The molecular layer of the cerebellar cortex contains inhibitory interneurons, but is dominated by PC dendrites and parallel fibers which are the axons of GCs (Butts et al., 2014). PCs develop earlier and initially secrete sonic hedgehog (Shh) which is essential for proliferation of GCPs (Wallace, 1999). Under an intricate regulatory system, the appropriate numbers, migration and positioning of these cells is required in order for synapse formation and assembly of the cerebellar cortical circuitry.

The cerebellar cortex, which is the location of the most of cerebellar neurons, is compartmentalized and the cytoarichtecture is the most elaborately patterned circuit of all the CNS structures (White and Sillitoe, 2013; Beckinghausen and Sillitoe, 2019). The molecular expression patterns, afferent/efferent fibers, and birthdates divide the cerebellar cortex into an array of parasagittal stripes (e.g., Voogd, 1967; Hashimoto and Mikoshiba, 2003; Sugihara and Shinoda, 2004; Pijpers et al., 2006; Apps and Hawkes, 2009; Marzban and Hawkes, 2011; Bailey et al., 2013; Rahimi-Balaei et al., 2016) and 
is further subdivided into four transverse zones (Sillitoe et al., 2005; Marzban et al., 2008; Marzban and Hawkes, 2011; Bailey et al., 2013, 2014; Rahimi-Balaei et al., 2016). The most extensive study of cerebellar cortex compartmentation was performed on PCs using zebrin II and phospholipase C beta 4, and resulted in a striking map of topographic stripes (Plc $\beta 4)$ e.g., (Marzban et al., 2007; Kim et al., 2009; Bailey et al., 2014). The cerebellar cortical interneurons are also organized and restricted to the same zone and stripes pattern (Consalez and Hawkes, 2013). In addition, stripes of the cerebellar cortex align with the terminal fields of the two major cerebellar afferent types; mossy fibers and climbing fibers (Akintunde and Eisenman, 1994; Sugihara and Shinoda, 2004; Sugihara and Quy, 2007; Rahimi-Balaei et al., 2015; Sillitoe, 2016). Remarkably, an interesting birth dating study has revealed that the zone and stripe pattern is established before migration of cerebellar neurons. It was found that, the fate of PC topography is already specified according to their birth date during E10.5-12.5 (Hashimoto and Mikoshiba, 2003). Recently, it has been shown that the CN neurons (CNNs) are organized with molecular heterogeneity that may mirror the molecular complexity of the cerebellar cortex (Sugihara and Shinoda, 2007; Chung et al., 2009a; Sugihara, 2011).

Underlying the complex cerebellar cytoarchitecture with a few neuronal types is an intricate sequence of events in which neurons that originate from different germinal zones migrate via a complicated migratory pathway to their final position and establish elaborate cerebellar compartmentation and circuits (Figure 1). The cerebellar glial cells migration are not included in this review because of complexity and the molecular processes involved and need to be discussed in a specific focused review article.

\section{Purkinje Cells Origin, Migration and Final Organization}

PCs, which are key neurons in the cerebellar cortex networking, complete their final mitotic division at E10.5-12.5 in mice (Hashimoto and Mikoshiba, 2003, 2004; Minaki et al., 2008). Once in the postmitotic stage, they start a short distance radial migration along the radial glial fibers (scaffold/substrate) from their site of origin in the VZ (Rakic and Sidman, 1970; Yuasa et al., 1996; Hatten, 1999). PCs exhibit an elongated morphology consistent with axonogenesis at E12.5, which is directed toward the mantle zone where they accumulate as an irregular multilayer of cells called the cerebellar plate, or PC plate (PCP) at E14.5 (Miyata et al., 2010). However, PC axons project to the $\mathrm{CN}$ by around E16 (in mice; Sillitoe et al., 2009) and around E18 (in rat; Eisenman et al., 1991). During the early stage of PC migration, PCs initially have a leading apical neurite and trailing process, and the cell's position changes during cerebellar primordium expansion and morphological development (Hatten and Heintz, 1995; Sotelo and Dusart, 2009). At E13, the somata of cerebellar radial glial cells-the precursor of Bergmann glia-are aligned along the surface of the 4th ventricle, and extend processes up to the pial surface of the cerebellar plate. Along with translocation of the radial glial somata from VZ, the PCs undergo delamination and migration which is quickly followed by the detachment of the trailing process of the radial glia from the VZ (Yuasa et al., 1996). The migration of PCs along radial glia has not been documented in live preparations and this assumption is based on still images. However, it is believed that the newborn Purkinje cells from the VZ migrate radially, along the processes of radial glia. Recently it was shown that those Purkinje cells originate from caudolateral VZ migrate tangentially and cross the radial glial fibers but not along with them (Miyata et al., 2010; Sotelo, 2017; Schilling, 2018). With this evidence it can be speculated that despite the tangentially oriented PCs, some of these cells use radial glial fibers for their migration. The fast proliferating VZ neuroepithelium leads to prominent bulging toward the 4th ventricle and the caudal appearance of the cerebellar primordium seems oriented horizontally. However, radial glial fibers are connected from the neuroepithelium to the subpial surface and provide substrates for the PCs that originated from the caudal VZ.

After $\sim$ E14.5 the PCP, a multi-cell-thick immature PC layer, is expanded in orchestra with the cerebellum development and aggregated in several PC clusters (PCCs) that become well established around E17.5 (Fujita et al., 2012). It appears that there is no migratory activity during this stage, but rather a small displacement of Purkinje cell groups following expansion of the developing cerebellum. The second wave of PC migration/displacement is initiated after formation of the PCCs. PCs disperse and arrange in a single regularly spaced monolayer during cerebellar expansion and simultaneously grow their axon and dendrites (Butts et al., 2014). During PC differentiation, they collapse their apical neurite (at P0) and form numerous short neurites at $\sim \mathrm{P} 6$ which develop ramified dendrites at $\sim$ P8 (Armengol and Sotelo, 1991). In humans, PC progenitors start their migration from the VZ at stages 18 and 19 of the development ( $\sim 44-48$ days; Müller and O'Rahilly, 1990). They form a monolayer at 16-28 weeks of the gestation, and start the cerebellar enlargement with the development of more dendritic branches, which is associated with an increase in synapse formation (Müller and O'Rahilly, 1990).

It is not clear how PCs disperse from the cluster stage to the monolayer position (Figure 1). One of the most studied molecules that is involved in controlling PC migration is the Reelin pathway (Larouche and Hawkes, 2006). During mouse cerebellar development, the expression of Reelin (Reln mRNA and glycoprotein) is first detected at E13, along the dorsal cerebellar surface corresponding to the RL-derived cells and the nuclear transitory zone (NTZ; Fink et al., 2006). It has been shown that the delamination of postmitotic lateral Purkinje cells (at around E10.5) from the ventricular neuroepithelium and their initial migration is independent on Reelin signaling because at this time-point Reelin expression in the cerebellum has not yet started (Yuasa et al., 1993). By the first week of postnatal life, Reelin expression disappears from the deep areas but is maintained in GCPs, and the expression of Reelin may continue in some GCs of adult mice (Fink et al., 2006). Dispersal of Purkinje cells from the clusteric stage is 


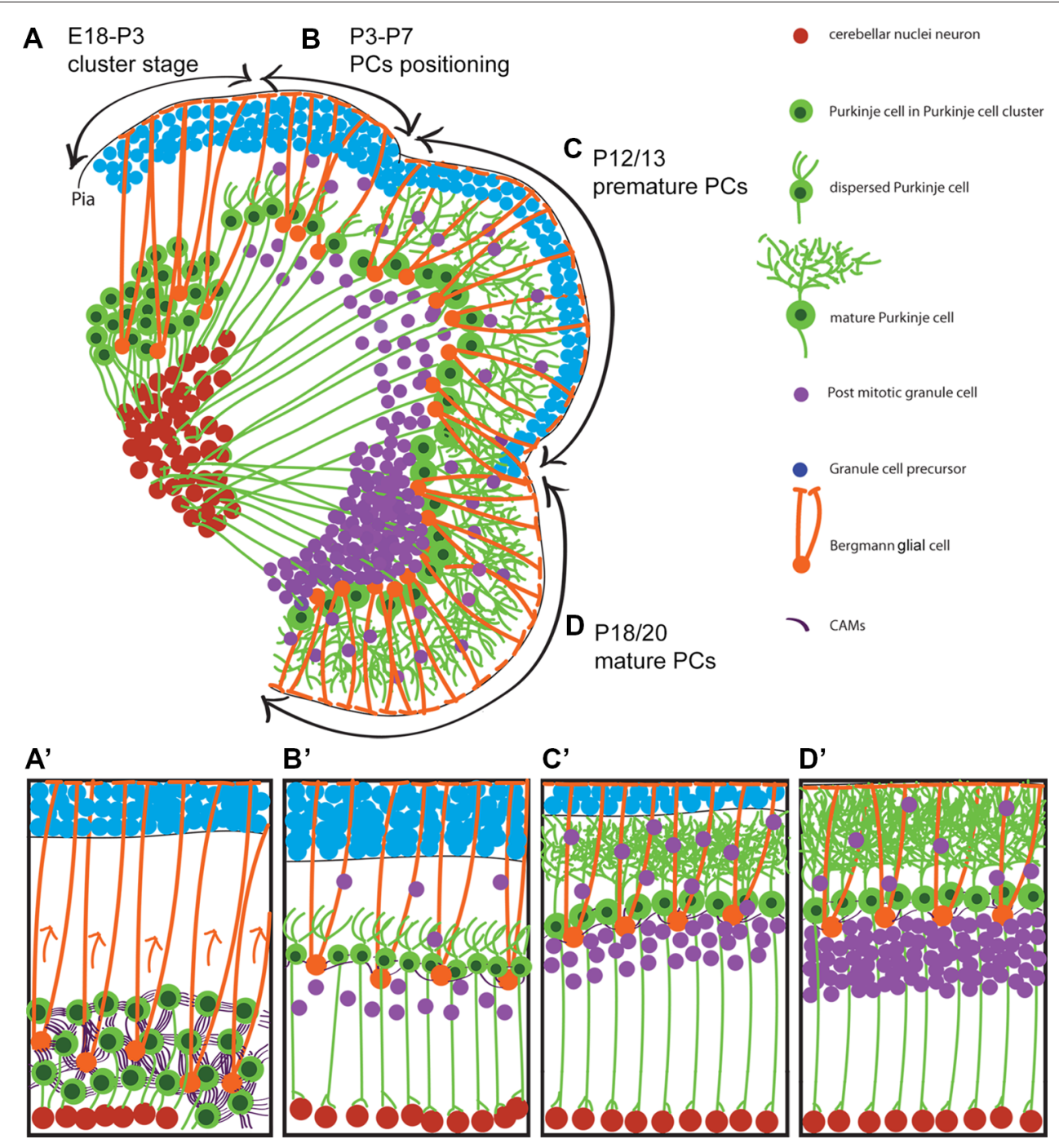

FIGURE 1 | Neuronal migration during postnatal cerebellar development. A schematic illustration of cerebellar development at sagittal section of postnatal mice. It shows that Purkinje cells (PCs) cluster disperse to establish PC monolayer and start maturation while granular layer form from external germinal zone (E18-P20). $\left(\mathbf{A}, \mathbf{A}^{\prime}\right)$ Around E18 to P3, PCs are in clusteric stage and show high CAMs connections between PCs-PCs and PCs-Bergmann glial cell body which is located beside PCs during clusteric stage and extend their fibers to the cerebellar pia surface. (B, $\left.\mathbf{B}^{\prime}\right)$ PCs in dispersal situation and positioning process (P3-P7) with less CAMs connections and show shortened Bergmann glial fibers. (C, $\left.\mathbf{C}^{\prime}\right)$ It shows how premature PCs (P12/13) arborized (maturation process) while granule cell precursors (GCPs) migrate to the developing granular layer and become mature GCs. (D,D') At around P18/20 is end stage of the PCs maturation and GCPs inward migration. P, postnatal day; E, embryonic day; CAMs, cell adhesion molecules.

dependent on Reelin expression and its downstream molecules apolipoprotein E receptor 2 (ApoER2) and very-low-density lipoprotein receptor (VLDLR). Reelin binds with similar affinity to ApoER2 and VLDLR. Disabled-1 (Dab1) which is a key molecule in the Reelin pathway, is expressed by Purkinje cells, as they settle underneath the Reelin-expressing cells of the external germinal zone (Fatemi, 2005; Miyata et al., 2010). Mutations in the Reelin gene (reeler mouse; D'Arcangelo et al., 1995), dab1 gene (scrambler and yotari mouse; Howell et al., 1997; Sheldon et al., 1997), and targeted deletion of the genes for both Apoer2 and Vldlr (Trommsdorff et al., 1999) all result in a similar phenotype of ectopic Purkinje cells due to a lack of dispersal from the cluster. These findings have placed Reelin, ApoER2, VLDLR and Dab1 into a common signaling pathway. It has been shown that the Reelin protein resembles extracellular matrix proteins that are involved in cell adhesion (D'Arcangelo et al., 1995) and regulate cadherin function via Dab1.

Cadherins are a group of transmembrane proteins that mediate cell-cell adhesion during tissue morphogenesis (Maitre and Heisenberg, 2013). Cadherin-6B (also known as cadherin-7) is overexpressed in Purkinje cell progenitors and is involved in guiding migrating neurons along neurites that express the same cadherin during their radial migration. These findings indicate that cadherin adhesive mechanisms are involved in neuronal guidance (Takei et al., 2000). It has also been 
shown that Dab1 signaling controls the adhesive property of neurons to radial glia. The newborn neurons in the cortex of scrambler mice remain attached to the process of their parental radial glia during the entire course of radial migration and this abnormal neuronal-glial adhesion is highly linked to the positional abnormality of neurons in scrambler mice. Additionally, the phosphorylation of tyrosine residues of Dab1 regulates $\alpha 3$ integrin levels in migrating neurons and their timely detachment from the radial glial fibers (Sanada et al., 2004). Furthermore, direct interaction of phosphorylated Dab1 with other intracellular proteins such as members of Crk (adapter molecule crk also known as proto-oncogene c-Crk or p38) family might connect the Reelin pathway to integrinmediated adhesion and migration of neurons (Ballif et al., 2004; Mayer et al., 2006). It has been shown that abnormal migration of neurons in scrambler mice is associated with an impaired detachment of neurons from clonally related radial glial cells. This abnormal neuronal-glial adhesion depends on $\alpha 3$ integrin signaling that is regulated by Dab1 (Sanada et al., 2004). However, a major challenge still remains: how do Purkinje cells from the clusteric stage disperse to their position in a monolayer?

It has been suggested that the PCC position changes during cerebellar surface development, which is extended rostrocaudally and mediolaterally and becomes arranged in a monolayer due to cerebellar expansion (Butts et al., 2014). In addition, GCs have been proposed to be a major player in the positioning of Purkinje cells postnatally (Jensen et al., 2002). However, several reports have shown that, Purkinje cells respond differently to different GC defects (such as hypoplasia, agenesis). In most cases, each affected cerebellum comprises several small percentages of Purkinje cells population, which are either in different ectopic locations, or arranged in the monolayer position. For example, a study of the math1 null-mutant mouse in which the external germinal zone does not form, three populations of ectopic Purkinje cells have been described (Jensen et al., 2002). In the scrambler (mutation in Dab1, Reelin adaptor protein), the cerebellum is small because the size of the GC population is severely diminished by $\sim 80 \%$ and approximately $95 \%$ of Purkinje cells (not all) fail to complete their migration (Goldowitz et al., 1997; Reeber et al., 2013). Chemokine receptor 4 (Cxcr4) deficiency results in a lower number of GCs in the cerebellum and partially disorganized ectopic Purkinje cells (Huang et al., 2014), which is very similar to the phenotype described in Weaver mice (Smeyne and Goldowitz, 1989; Chen et al., 2009). It has been suggested that protein tyrosine phosphatase, non-receptor type 11 (Ptpn11) regulates formation of the laminar cerebellar cortex by controlling GC migration via the Cxcl12/Cxcr4 signaling (Hagihara et al., 2009), although removing Ptpn11 in the external germinal zone has no distinct effect on cerebellar corticogenesis ( $\mathrm{Li}$ et al., 2014). These results indicate that GCs are not the main player driving Purkinje cell organization in the cerebellum. Such an elaborate Purkinje cell monolayer organization cannot be explained by surface expansion and GC development. The development of this monolayer organization must be precisely regulated by active cellular and molecular processes rather than by a passive expansion.

Do PCs use any substrates or cells such as Bergmann glia cells to disperse from the clusteric stage to their final destination? Sudarov and Joyner (2007) introduced the role of GCs and Bergmann glia during formation of the base of each fissure (as an anchoring center) and proposed that this dictates the shape of the folia. Bergmann glia are defined as PC-associated astrocytes and are a specific type of astrocyte, which are zonally organized in the cerebellar cortex (Reeber et al., 2018). Bergmann glial cells originate from radial glia within the VZ. The radial glia transform to Bergmann glial cells during E14.5-E18.5 (in mice) under control of Ptpn11, which maintains the basal processes of the radial glia and relocates somata from the VZ to the nascent PCCs (Yuasa, 1996; Li et al., 2014). It is well documented that Bergmann fibers are associated with GCs in migration during cerebellar postnatal development, and this is the origin of the concept of glia-guided neuronal migration (Hatten, 1990). Recently, it was suggested that Bergmann glial cells are essential in cerebellar corticogenesis, especially through monolayer formation of Purkinje cells, dendritogenesis, migration of GCs, and circuit formation (Cajal, 1911; Rakic, 1971; Altman and Bayer, 1997; De Zeeuw and Hoogland, 2015; Leung and Li, 2018). Yamada et al. (2000) showed that not only are Bergmann glial cells associated with Purkinje cells in the adult cerebellum but they are also associated with Purkinje cells during their migration, dendritogenesis, synaptogenesis and maturation (Yamada and Watanabe, 2002). It is still controversial whether Bergmann glia regulate Purkinje cell monolayer formation through Notch-RBPJ signaling and notch ligand, Delta-like 1 (Komine et al., 2007; Hiraoka et al., 2013), since ablation of genes from Bergmann glia does not affect Purkinje cell monolayer formation while ablation of Dner (delta/notch-like EGF receptor containing) from Purkinje cells results in Bergman glia disruption (Eiraku et al., 2005; Tohgo et al., 2006; Greene et al., 2016). Bergman glia are rich in glutamate receptors and transporters [SLC1A3 (GLASTs) or the excitatory amino acid transporter, EAAT1] that are involved in Purkinje cell synapse formation (O'Hearn and Molliver, 1997). In fetal and neonatal stages, SLC1A3 is expressed ubiquitously in cerebellar radial glia or astrocytes and excessively in Bergmann glia at the postnatal stage (Yamada et al., 2000). It has been shown that the dendrites of the growing Purkinje cells ascend through the $\mathrm{GFAP}^{+} / \mathrm{SLC}_{\mathrm{A}} 3^{+}$rod-like Bergmann fibers to reach the external granular layer (Yamada et al., 2000; Yamada and Watanabe, 2002). Studies on the reeler and weaver mutants has shown that SLC1A3 is down regulated in cerebellar astrocytes associated with Purkinje cells (Fukaya et al., 1999).

Reelin is also important for GFAP positive glial cell differentiation, process extension and orientation (Forster et al., 2006). In comparison to wild type mice, reeler mutant mice have unusual, numerous and heavily stained astrocytes with GFAP (Benjelloun-Touimi et al., 1985). Interestingly, in scrambler mutant mice, the cerebellum is small with no foliation, with GCs placed normally but their number reduced, and Purkinje 
cell numbers decreased and placed ectopically (Goldowitz et al., 1997). Goldowitz et al. (1997) showed that the effects of Reelin on Purkinje cells could also be mediated indirectly by Bergmann glia. Although these studies indicate the role of the Reelin pathway in neuronal migration and Bergmann glia cell development, there is no evidence that Purkinje cells are using somal transduction or glial guided migration (Schilling, 2018). Therefore, it is possible that Purkinje cells utilize a different mode of migration in which they disperse passively with the assistance of a pulling force from the Bergmann glia by regulating cell adhesion molecules to form a Purkinje cell monolayer (Figure 1). This should be examined in future studies.

\section{GABAergic Interneurons (Stellate/Basket and Golgi Cells)}

Precursors of stellate and basket cells are generated within the VZ prenatally (when they express the paired homeobox gene, Pax2) and then migrate from the cerebellar plate to the developing white matter and postnatally (in mice) through the folial white matter while continuing to undergo cell division (Wefers et al., 2018). Thereafter, they migrate radially towards the molecular layer to accumulate at the inner border of the external granular layer and then migrate tangentially before settling at their final position within the molecular layer. A new study published by Wefers et al. (2018) document that the movement of cerebellar interneurons, basket cells and stellate cells, are highly directed and rerouted to the molecular layer during their transit through the nascent cerebellar cortex. They also showed that both the speed and directional persistence of basket cells and stellate cells are larger in the nascent GC layer than in the molecular layer (Wefers et al., 2018).

Golgi cell precursors are GC layer inhibitory interneurons and are born prenatally within the VZ. From the cerebellar plate these cells migrate to developing white matter while continuing proliferation during the migration until around P4 (Zhang and Goldman, 1996; Weisheit et al., 2006). During the perinatal development, Golgi cell precursors continue the migration through the developing folial white matter and terminate migration postnatally within the developing granular layer (Maricich and Herrup, 1999). In addition, a subset of Golgi cells are derived from the external germinal zone (Chung et al., 2011). These cells migrate within the white matter and become postmitotic postnatally and then migrate to position within the granular layer (Yamanaka et al., 2004; Wefers et al., 2018).

Although the mode and direction of migration of the GABAergic interneurons of the cerebellar cortex is a complex process and not entirely clear from origin to final position. However, based on the evidence the migration within the cerebellar cortex could be in the random walk mode.

\section{Granule Cell Origin, Migration and Final Destination}

The GCPs that originate in the RL (Atoh1 expressing progenitors) migrate tangentially through a subpial stream pathway, and over the cortical surface to form the external germinal zone, similar to the rostral migratory stream from the ganglionic eminences to the olfactory bulb (Komuro and Yacubova, 2003; Stenman et al., 2003; Machold and Fishell, 2005). Simultaneously, GCPs co-express Pax6, Meis1, Zic1/2 and Barhl1 while post mitotic (mature) GCs do not express Atoh1 (Stoykova and Gruss, 1994; Ackerman et al., 1997; Miyata et al., 1999; Morales and Hatten, 2006). Although the existence of a substrate or scaffold in tangential migration has not been confirmed, it is possible that the pial meninges have this role as these processes are present underneath the pial surface (Komuro and Yacubova, 2003). In addition, the external germinal zone is unique among proliferative germinal zones of the CNS as it is adjacent to the pial surface rather than the ventricular surface. The cells in this layer are highly proliferative, generating an enormous number of granule cell progeny, thereby greatly increasing the thickness of the external germinal zone. In mice at E12.5 to E17, GCPs are born and migrate to establish the external germinal zone (postmitotic GCs typically sojourn for 1-2 days within the lower layers of the external germinal zone) and give rise to GCs during the first two postnatal weeks (Figure 1; Komuro et al., 2001; Wang and Zoghbi, 2001). In humans, the external germinal zone is distinguished as a distinct layer between 10 weeks gestation to 2 month postnatally and will disappear by about year one and a half (Marzban et al., 2015). GCs initially follow a tangential migration and after proliferation in the external germinal zone, the cells migrate radially. The GCs situated in the inner layers of the external germinal zone start redial migration along Bergmann glial fiber to form the granular layer while expressing NeuroD1 (an early marker of the differentiated GCs). The expression of Unc5h3 and Pax6 continues throughout the life span (Komuro and Yacubova, 2003). The granule cells also change from a round cell to a more horizontal-oriented shape as they begin to extend axons tangential to the cortical surface. The CXCR4, a G-protein-coupled chemokine receptor, is broadly expressed in cells of the CNS and can mediate migration in response to its ligand, stromal derived factor 1 (SDF-1; also known as chemokine ligand 12, CXCL12). The CXCR4/CXCL12 signaling pathway is involved in the migration of GCPs in the rostral migratory stream from the RL. The alterations in this pathway result in the movement of GCPs toward deeper positions away from the meninges, i.e., the inward radial migration, to form the granular layer (Leto et al., 2016). In the GC migration pathway, Sema6A functions in the switch from tangential migration in the external germinal zone to radial migration along Bergmann glia (Leto et al., 2016).

These postmitotic GCs migrate radially inward from the external germinal zone and pass by the developing Purkinje cell layer, to generate the granular layer. The cells migrate along the processes of the Bergmann glia, which is only present in the cortex of the cerebellum (Figure 1). Electron microscopic studies have detected Bergmann fibers in the external germinal zone by E15.5 in mice, and by 9 weeks gestation in humans (Choi and Lapham, 1980). The radial migration of the cerebellar granule neurons depends on actomyosin of the leading-process which coordinates organelle positioning and adhesion receptor dynamics (Ballif et al., 2004). During cerebellar development, 
DCX is strongly expressed by migratory GCs (as occurs in Purkinje cells) to mediate coupling of the nucleus to the centrosome (Gleeson and Walsh, 2000; Deutsch et al., 2010). Shh which is expressed by Purkinje cells plays a key role in GC proliferation, and may also provide a stop signal for GC proliferation and the beginning of the terminal differentiation as these cells migrate toward the source of Shh in Purkinje cell layer (Lewis et al., 2004). On the other hand, it is possible that the migration and maturation of GCs is not associated with Shh pathway signaling, but rather the subsequent loss of precursor cells from the external germinal zone limits the period over which postmitotic GCPs are generated (Lewis et al., 2004). The cellular and molecular mechanisms of cerebellar GC migration is reviewed by Yacubova and Komuro (2003).

\section{Cerebellar Nuclei Neurons Origin, Migration and Final Destination}

During the early stages of the cerebellar development Atoh1expressing neural progenitors, which arise from the RL at around E9.5-12.5, give rise to the excitatory (glutamatergic) CN projection neurons (Manto et al., 2013; Marzban et al., 2015). The CNN precursors migrate tangentially from the $\mathrm{RL}$ through the rostral migratory stream to midway of the cerebellar primordium and then change direction toward the NTZ, a transient cell mass that is subsequently partitioned and organized to form the medial, interposed and lateral CN (Fink et al., 2006; Kurosaka and Kashina, 2008). During development of the glutamatergic CNNs, transcription factors Pax6, Tbr2, Tbr1 and Lmx1a are expressed sequentially within the neurons of the RL and the NTZ (Fink et al., 2006). It has been shown that Tbr1 knockout mice have a similar number of CNNs, but the boundaries are not properly delineated (Fink et al., 2006). Neuroblasts that express Pax6/Reelin move radially to become Tbr2 positive cells (Fink et al., 2006). The formation of the dentate nucleus (the largest and most lateral cerebellar nucleus) begins by stage 20 (52 days in humans) when precursors (interneurons INs and projection neurons) migrate radially from the $\mathrm{VZ}$ and rostromedially from the $\mathrm{RL}$ (Marzban et al., 2015). In mice, projection neurons of $\mathrm{CN}$ originate from the $\mathrm{RL}$ and unipolar neuroblasts migrate in the subpial stream toward the NTZ under the guidance of both diffusible Netrin (a family of laminin-related secreted proteins) and Slit (an extracellular matrix protein; Fink et al., 2006; Guerrini and Parrini, 2010; Matsuki et al., 2013; Qin et al., 2017). Interestingly, a study using quail-chick chimeras has shown that the rostromedial end of the cerebellar primordium originates from the alar plate of the caudal mesencephalon (Hallonet and Alvarado-Mallart, 1996). By mapping the Ptfla promoter with a reporter, it was shown that the $\mathrm{VZ}$ only gives rise to inhibitory neurons of the CN. Thus the CNNs are assembled in a coordinated fashion through integration of $\mathrm{PTF} \mathrm{a}^{+}$and $\mathrm{ATOH}_{1}{ }^{+}$lineages in local circuits that migrate from two different germinal zones (Leto et al., 2016). Nichols and Bruce (2006) hypothesized that the mesencephalic neural crest is the source of several migratory streams and it is the dorsal intermediate stream that gives rise to the neurons of the $\mathrm{CN}$.
During brain development, in the majority of brain regions (including $\mathrm{CN}$ ) the CXCR4/CXCL12 signaling pathway is the most important signaling pathway that regulates neuronal migration. This receptor first appears in immature neurons in the RL at E12.5 (Tissir et al., 2004) and the expression of this receptor continues in the $\mathrm{RL}$-derived $\mathrm{CN}$ precursors during the rostral subpial migratory stream pathway to the NTZ. Their ligand CXCL12 is expressed simultaneously in the meninges overlying this migratory pathway. Similar to tangential migration of GCPs, this indicates the potential interaction of CXCR4- and CXCL12-expressing cells in the rostral migratory stream. This may facilitate the rostral migration of RL-derived neurons and also change the direction of the migration toward the NTZ. This occurs through the detachment of neurons in this region from the pial surface to descend toward deeper positions in the NTZ (Tissir et al., 2004).

Although there is some evidence for tangential migration of CNNs from the RL subpially to the midway of the cerebellar primordium, the mode of the migration and the substrate utilized during the change of the direction from the pial surface of the cerebellar primordium to the NTZ are not known. Furthermore, the mode of migration and the substrate pathway for the putative subset of mesencephalic derived cerebellar nuclear neurons are also not clear and need to be addressed.

\section{Unipolar Brush Cell Origin, Migration, Final Position}

UBCs project directly to GCs and amplify vestibular inputs to the cerebellum. In mice, the UBCs are generated from E13.5 to the early neonatal period (P0.5; Marzban et al., 2015). These cells originate from the RL and migrate through the developing white matter before settling in the GC layer of the cerebellar cortex (Hevner et al., 2006). The translocation of the UBCs from white matter to GC layer occurs between P3 to $\mathrm{P} 10$ and these cells sojourn in white matter for a period of time (Englund et al., 2006). Loss of the neurofibromatosis type 1 (Nf1) gene leads to imbalance in generating the appropriate numbers of glial cells, GC/UBC fate-specification/differentiation and GC/UBC migration (Kim et al., 2014). Studies have also shown a role for DCX in the neurogenesis and migration of UBCs (Manohar et al., 2012; Paolone et al., 2014). Furthermore, Wnt1 glycoprotein expression in the upper RL and UBCs is related to molecular identity and cell migration in cerebellar development (Hagan and Zervas, 2012). A previous study by Englund et al. (2006), reported that Tbr2 positive UBCs migrated from RL explants directly into the developing white matter of adjacent cerebellar slices (Hevner et al., 2006).

\section{ANIMAL MODELS IN NEURONAL MIGRATION}

The use of animal models is a powerful approach to understand both human disease and basic biology (Schofield et al., 2012). Several human developmental malformations have been attributed to defects in neuronal migration and have been 
TABLE 2 | Mutant mice models with cerebellar neuronal migration defects.

\begin{tabular}{|c|c|c|}
\hline Mouse model & Gene & Function \\
\hline $\begin{array}{l}\text { Reeler (like lissencephaly } 2 \text { or } \\
\text { Norman-Robert syndrome in } \\
\text { human) }\end{array}$ & Reln & $\begin{array}{l}\text { Neuronal migration (Purkinje cel } \\
\text { in cerebellum and pyramidal cell } \\
\text { in cerebral cortex) }\end{array}$ \\
\hline Scrambler & Dab1 & $\begin{array}{l}\text { The Reelin-Dab1 signaling } \\
\text { pathway involves in neuronal } \\
\text { migration and also in lamination }\end{array}$ \\
\hline VLDLR/ApoE2 & VLDLR/ApoE2 & $\begin{array}{l}\text { Reelin receptors involves in } \\
\text { neuronal migration and also in } \\
\text { lamination }\end{array}$ \\
\hline Src/Fyn & Src/Fyn & $\begin{array}{l}\text { Downstream molecules of Reeli } \\
\text { signaling pathway involves in } \\
\text { neuronal migration and also in } \\
\text { lamination }\end{array}$ \\
\hline Straggerer & $R O R a$ & $\begin{array}{l}\text { RORa is a gene expressed only } \\
\text { in Purkinje cells in the } \\
\text { olivocerebellar circuit }\end{array}$ \\
\hline Pten & Pten & $\begin{array}{l}\text { Pten express in Bergmann glia } \\
\text { (scaffold) }\end{array}$ \\
\hline SmoA2 & SmoA2 & Member of SHH pathway \\
\hline
\end{tabular}

Naked Ataxic (nax)

Acp2

p35/Cdk5

p35/Cdk5

Girk2

$\begin{array}{ll}\text { Weaver } & \text { Girk2 } \\ \text { Rp58 } & \\ & \text { Rp58 } \\ & \\ \text { CXCR4- and SDF-1 deficient } & \text { CXCR4- and } \\ & \text { SDF-1(aka } \\ & \text { CXCL12) }\end{array}$

Astn or Pex2

Astn or Pex2

$B D N F$

BDNF

$\begin{array}{ll}\text { Rb/p107 } & R b / p 107 \\ \text { VPS18 } & \text { VPS18 } \\ \text { MDM2 } & \text { MDM2 }\end{array}$

Tbr1

Tbr1
Cyclin-dependent kinase 5 and its regulator, p35 involve in neuronal migration, proliferation and neurite outgrowth G protein-activated inward rectifier potassium channel 2

GABAergic and Glutamatergic neuron development

The chemokine receptor 4 (CXCR4)-chemokine ligand 12 signaling pathway involve in neuronal migration and proliferation

Genes for glial-guided neuronal migration

Purkinje cells provide BDNF and promote granule cells precursors to differentiate and migrate along Bergmann glia fibers

Survival of granule cells

Disrupting multiple vesicle transport pathways to lysosomes

Link between p53 and Shh signaling pathways in granular neuronal precursors

Cerebellar nuclei migration

\section{Defect}

Ectopic Purkinje cell cluster ( 80\%), no foliation, cerebellar hypoplasia

Ectopic Purkinje cell cluster, no foliation, cerebellar hypoplasia

Ectopic Purkinje cell cluster, no foliation, cerebellar hypoplasia

Ectopic Purkinje cell cluster, no foliation, cerebellar hypoplasia

Purkinje cells are small, ectopic, possess rudimentary dendritic arbors and their number is reduced by about $75 \%$. All of the granule cells and $60 \%$ of the inferior olivary neurons die during the first postnatal month.

Ectopic Purkinje cells and Purkinje cell dendritic arborization

Ectopic clusters of Purkinje cells with disorganized dendritic arbors and axonal collaterals

Excessive migration of Purkinje cells to the molecular layer, no Purkinje cell monolayer formation, cerebellar hypoplasia, reduced granule cells proliferation

Normal gross morphology, folia and lamination. Molecular layer with more cell density (GCs) and ectopic PCs in granular layer

Beside PCs and GCs death, neuronal migration defect as a result of Bergman glia abnormality

Severe cerebellar hypoplasia and developmental failure of Purkinje cells, Bergmann glia and granule cells Abnormal cerebellum, ectopic PCs, irregular external germinal zone

Ectopic granule cells precursors, abnormal Purkinje cell dendrite development, and external germinal zone present until late childhood cerebellum

Defects in cerebellar patterning such as ectopic granule cells precursors

Purkinje cells are disarranged with dystrophic dendrites

Neurodegeneration and impaired neuronal migration

Reduced levels of MDM2 and increased levels of p53 have small cerebella with shortened folia, reminiscent of deficient Shh signaling

Defect in medial cerebellar nuclei plus lateral and interpose

\section{Reference}

Goffinet (1983), Yuasa et al. (1993) and Miyata et al. (2010)

Chung et al. (2007, 2009b)

Reddy et al. (2011)

Kuo et al. (2005)

\author{
(
}

Hadj-Sahraoui et al. (1997)

Yue et al. (2005)

Armengol and Sotelo (1991) and Dey et al. (2012)

Mannan et al. (2004); Bailey et al. (2013, 2014);

Rahimi-Balaei et al. (2016,

2018) and unpublished data

Chae et al. (1997)

Rakic and Sidman (1973)

Baubet et al. (2012)

Ma et al. (1998), Larouche and Hawkes (2006) and

Huang et al. (2014)

Faust (2003)

Borghesani et al. (2002)

Marino et al. (2003) and Sotelo and Dusart (2009)

Peng et al. (2012) and Davies (2013)

Malek et al. (2011) and

Gil-Sanz et al. (2013)

Fink et al. (2006) 
confirmed in mouse models in which a gene mutation results in abnormal neuronal migration (Table 2).

In reeler knockout mice, the first manifestation of PCP malformation is at E14.5 and is prominent during cerebellar foliation at around E17.5 (Goffinet, 1983; Yuasa et al., 1993; Hadj-Sahraoui et al., 1997). This is mutation produces severe disorders in cellular migration throughout the brain and in the cerebellum it results in defects in Purkinje cell positioning, decreased proliferation and migration of GCs, and abnormality in foliation (Trommsdorff et al., 1999). The reduction and migratory defects observed in GCs could be due to Shh insufficiency caused by ectopically located Purkinje cells, which is far away from external germinal zone. The number of UBCs is also decreased and the cells are not positioned correctly (Trommsdorff et al., 1999). Interestingly, while there is no abnormality in the development of the NTZ in reeler knockout mice, the $\mathrm{CN}$ are significantly affected. The organization within the $\mathrm{CN}$ is especially disrupted in the lateral and medial $\mathrm{CN}$. However, it has also been reported that alterations in the expression of the genes encoding the proteins in the Reelin signaling pathway do not change the morphology of the $\mathrm{CN}$ in mice. These components of Reelin pathway are cell surface receptor molecules VDLR/ApoER2, and intracellular signaling molecules Dab1, and tyrosine kinases Src and Fyn. In Dab-1 mutant, scrambler mice, neurons show increased adhesion to radial glia which prevents them from reaching their final destination. These mice are ataxic and exhibit several neuroanatomical defects reminiscent of reeler mice. These findings indicate that abnormalities in the regulation of Reelin pathway result in cerebellar cortex anomalies which also result in defects in the development of CN (Fatemi, 2005).

In mice with a point mutation in the Lysosomal Acid phosphatase 2 (Acp2) gene, the result is a cerebellar defect with excessive migration of Purkinje cells to the molecular layer (Bailey et al., 2013, 2014; Rahimi-Balaei et al., 2016, 2018). We have recently investigated the role of Reelin-Dab1 signaling and its relationship to Erk1/2 (a member of mitogen activated kinases family) during Purkinje cell monolayer formation in the Acp2 mutant cerebellum. Our findings indicate that down regulation of Reelin together with up regulation of phospho-Dab1 leads to the excessive and incorrect Purkinje cell migration in the Acp2 mutant mice (under revision; Ashtari, 2017). In addition, it has been shown that the vacuole protein sorting 18 (VPS18), a core protein in intracellular vesicle transport, is involved in neuronal survival and CNS development. Genetic deletion of VPS18 leads to neurodegeneration and impaired neuronal migration as a result of disruption of multiple vesicle transport pathways that produce lysosomes. These findings indicate the importance of lysosomes in neuronal migration (Peng et al., 2012).

It is known that mouse double minute 2 homolog (MDM2), also known as E3 ubiquitin-protein ligase is a link between p53 and Shh. Using a p53 inhibitor it was shown that MDM2 is part of a signaling pathway in the development of GCs. It was reported that mice with reduced levels of MDM2 and increased levels of p53 have small cerebella with shortened folia, and Purkinje cells remained multi-layered and disorganized and exhibit stunted dendritic arborizations (Malek et al., 2011).
It has been shown that the lack of either Astn or Pex2 (genes for glial-guided neuronal migration) produces a slowed migration pattern of GCPs which results in the formation of ectopic GCPs, abnormal Purkinje cell dendrite development, and the external germinal zone remains present until late childhood (Faust, 2003). Purkinje cells are an important source of brainderived neurotrophic factor (BDNF) which promotes GCPs to differentiate and migrate along Bergmann glial fibers. Indeed, mice lacking BDNF have defects in cerebellar patterning such as ectopic GCPs (Borghesani et al., 2002). Finally, the deletion of CXCR4 leads to the premature migration of GCPs away from the proliferative zone of the external germinal zone, and small numbers of GCPs are found ectopically outside of the external germinal zone (Ma et al., 1998). Mouse models of fetal alcohol spectrum disorders and Minamata disease (a result of exposure to alcohol or methyl mercury during development) are also associated with deficits in GC migration related to interruption of $\mathrm{a} \mathrm{Ca}^{2+}$ /cyclic nucleotide signaling pathway (Komuro et al., 2015).

Another study by Baubet et al. (2012) has shown that the ablation of $58 \mathrm{KDa}$ repressor protein ( $\mathrm{Rp} 58$ ) results in severe cerebellar hypoplasia and failure of Purkinje cells, Bergmann glia and granule cells to develop properly which leads to a delay in the formation of the primary fissure, number of folia and defective lamination of the cerebellar cortex. Marino et al. (2003) have investigated the role of $\mathrm{Rb} / \mathrm{p} 107$ in the development of the cerebellum; and have shown that it is involved in the survival of granule cells. In Rb-deficient and $\mathrm{Rb} / \mathrm{p} 107$ double mutants, Purkinje cells are disarranged with dystrophic dendrites. In Phosphatase and tensin homolog (Pten) mutant mice ectopic Purkinje cells are present (Yue et al., 2005). Similarly in mice with a genetic deletion of either smoothened (SmoA2, member of Shh pathway) or Cxcr4, ectopic clusters of Purkinje cells are present with disorganized dendritic arbors and axonal collaterals (Dey et al., 2012; Huang et al., 2014).

Early postnatal mice with a mutation in $T b r 1$, have abnormal morphogenesis of the medial $\mathrm{CN}$ suggesting that migration defects are associated with malformation of this region of cerebellum. It is important to note that Tbr1 mutation is associated with the irregular formation of medial $\mathrm{CN}$, as well as irregular formation of interposed and lateral nuclei. Interestingly, although there are some histologic malformations following Tbr 1 mutation, these changes are not correlated with the neuronal loss, cell death, or axonal abnormalities (Fink et al., 2006).

\section{NEURONAL MIGRATION DISORDERS}

Neuronal migration and positioning are critical processes during CNS development and circuitry formation, and defects in neuronal migration can lead to devastating brain diseases (Manto et al., 2013). It is well known that malfunctioning of the migratory process causes neuronal migration disorders (NMDs). NMDs are a heterogeneous group of birth defects with the same etiopathological mechanisms caused by the abnormal migration of neurons in the developing brain. This can result in neurological disorders with clinical manifestations including schizophrenia, autism, ataxia and epilepsy (Gleeson and Walsh, 
2000; Nadarajah et al., 2003; Deutsch et al., 2010; Guerrini and Parrini, 2010; Demkow and Ploski, 2015; Marzban et al., 2015; Qin et al., 2017). The role of the Reelin pathway in neuronal migration has been extensively studied and in humans homozygous mutations in the RELN gene are associated with ataxia, cognitive abnormalities and cerebellar hypoplasia. In this context it has been also shown that the abnormal migration of cortical neurons is associated with reduced number of cortical gyri (lissencephaly). These results suggest an important role for Reelin in neuronal migration during the development. It should be noted that decreased levels of RELN expression have severe negative effects on the development of the human brain and may result in psychiatric diseases. For instance, patients who suffered from schizophrenia had reduced levels of RELN expression in the inhibitory neurons of their cortical areas. Additionally, decreased expression of Reelin has been observed in patients with other mental diseases, such as autistic-like disorders, bipolar disorder and major depressive disorder. Together these results suggest that Reelin has an important role in neuronal migration and synapse formation and deficits in Reelin expression may contribute to the pathophysiology of these disorders (Fatemi, 2005).

\section{CONCLUSION}

Neuronal migration is all about: where do neurons come from (origin), where do they go (neuronal migration pathway), and what are they going to become (differentiated neurons

\section{REFERENCES}

Ackerman, S. L., Kozak, L. P., Przyborski, S. A., Rund, L. A., Boyer, B. B., and Knowles, B. B. (1997). The mouse rostral cerebellar malformation gene encodes an UNC-5-like protein. Nature 386, 838-842. doi: 10.1038/386 $838 \mathrm{a} 0$

Akintunde, A., and Eisenman, L. M. (1994). External cuneocerebellar projection and Purkinje cell zebrin II bands: a direct comparison of parasagittal banding in the mouse cerebellum. J. Chem. Neuroanat. 7, 75-86. doi: 10.1016/08910618(94)90009-4

Altman, J., and Bayer, S. A. (1997). Development of the Cerebellar System: in Relation to Its Evolution, Structure and Functions. New York, NY: CRC Press.

Apps, R., and Hawkes, R. (2009). Cerebellar cortical organization: a one-map hypothesis. Nat. Rev. Neurosci. 10, 670-681. doi: 10.1038/ nrn2698

Armengol, J.-A., and Sotelo, C. (1991). Early dendritic development of Purkinje cells in the rat cerebellum. a light and electron microscopic study using axonal tracing in 'in vitro' slices. Dev. Brain Res. 64, 95-114. doi: 10.1016/01653806(91)90213-3

Ashtari, N. (2017). Cerebellar corticogenesis in the lysosomal acid phosphatase (acp2) mutant mice: purkinje cell migration disorder. Available online at: http://hdl.handle.net/1993/32254

Bailey, K., Rahimi Balaei, M., Mannan, A., Del Bigio, M. R., and Marzban, H. (2014). Purkinje cell compartmentation in the cerebellum of the lysosomal acid phosphatase 2 mutant mouse (nax-naked-ataxia mutant mouse). PLoS One 9:e94327. doi: 10.1371/journal.pone.0094327

Bailey, K., Rahimi Balaei, M., Mehdizadeh, M., and Marzban, H. (2013). Spatial and temporal expression of lysosomal acid phosphatase 2 (ACP2) reveals dynamic patterning of the mouse cerebellar cortex. Cerebellum 12, 870-881. doi: 10.1007/s12311-013-0502-y

Ballif, B. A., Arnaud, L., Arthur, W. T., Guris, D., Imamoto, A., and Cooper, J. A. (2004). Activation of a Dab1/CrkL/C3G/Rap1 pathway in Retzius cells instruct neuronal. Curr. Biol. 14, 606-610. doi: 10.1016/j.cub.2004.03.038 and positioning)? Given that different subsets of neurons may migrate long or short distances in different modes and directions before the positioning, there is no doubt that an accurate and precise regulation of neuronal migration is necessary in order to establish the appropriate neuronal architecture and perturbations during development can result in neuronal migration disorders. During the development of the brain, proliferative germinal zones have two important tasks which are: (1) to produce the right number of cells for the particular brain region (either too many or too few will result in abnormalities); and (2) to produce the right class of cells that need to migrate to the right position. The delineation of the regulation of these two tasks is a major goal of developmental neuroscience. In this review we have examined neuronal migration and its different modes with a focus on cerebellar cell types.

\section{AUTHOR CONTRIBUTIONS}

All authors listed have made a substantial, direct and intellectual contribution to the work, and approved it for publication.

\section{FUNDING}

This study was supported by grants from the Natural Sciences and Engineering Research Council of Canada (HM: NSERC Discovery Grant \# RGPIN-2018-06040) and the ALS CanadaBrain Canada Arthur J. Hudson Translational Team Grant (JK, HM).

Baubet, V., Xiang, C., Molczan, A., Roccograndi, L., Melamed, S., and Dahmane, N. (2012). Rp58 is essential for the growth and patterning of the cerebellum and for glutamatergic and GABAergic neuron development. Development 139, 1903-1909. doi: 10.1242/dev.075606

Beckinghausen, J., and Sillitoe, R. V. (2019). Insights into cerebellar development and connectivity. Neurosci. Lett. 688, 2-13. doi: 10.1016/j.neulet.2018.05.013

Benjelloun-Touimi, S., Jacque, C. M., Derer, P., De Vitry, F., Maunoury, R., and Dupouey, P. (1985). Evidence that mouse astrocytes may be derived from the radial glia. an immunohistochemical study of the cerebellum in the normal and reeler mouse. J. Neuroimmunol. 9, 87-97. doi: 10.1016/s0165-5728(85)80009-6

Bielle, F., Griveau, A., Narboux-Nême, N., Vigneau, S., Sigrist, M., Arber, S., et al. (2005). Multiple origins of Cajal-Retzius cells at the borders of the developing pallium. Nat. Neurosci. 8, 1002-1012. doi: 10.1038/nn1511

Borghesani, P. R., Peyrin, J. M., Klein, R., Rubin, J., Carter, A. R., Schwartz, P. M., et al. (2002). BDNF stimulates migration of cerebellar granule cells. Development 129, 1435-1442.

Bortone, D., and Polleux, F. (2009). KCC2 expression promotes the termination of cortical interneuron migration in a voltage-sensitive calcium-dependent manner. Neuron 62, 53-71. doi: 10.1016/j.neuron.2009.01.034

Butts, T., Green, M. J., and Wingate, R. J. (2014). Development of the cerebellum: simple steps to make a 'little brain'. Development 141, 4031-4041. doi: 10.1242/dev.106559

Cajal, S. R. (1911). Histologie Du Systéme Nerveux De L'homme \& Des Vertébrés. Paris: Maloine.

Chae, T., Kwon, Y. T., Bronson, R., Dikkes, P., Li, E., and Tsai, L.-H. (1997). Mice lacking p35, a neuronal specific activator of Cdk5, display cortical lamination defects, seizures, and adult lethality. Neuron 18, 29-42. doi: 10.1016/s08966273(01)80044-1

Chen, K. A., Lanuto, D., Zheng, T., and Steindler, D. A. (2009). Transplantation of embryonic and adult neural stem cells in the granuloprival cerebellum of the weaver mutant mouse. Stem Cells 27, 1625-1634. doi: 10.1002/stem.83

Chen, G., Sima, J., Jin, M., Wang, K.-Y., Xue, X.-J., Zheng, W., et al. (2008). Semaphorin-3A guides radial migration of cortical 
neurons during development. Nat. Neurosci. 11, 36-44. doi: 10.1038/ nn 2018

Choi, B. H., and Lapham, L. W. (1980). Evolution of bergman glia in developing human fetal cerebellum: a golgi, electron microscopic and immunofluorescent study. Brain Res. 190, 369-383. doi: 10.1016/0006-8993(80) 90280-2

Chung, S. H., Marzban, H., Aldinger, K., Dixit, R., Millen, K., Schuurmans, C., et al. (2011). Zac1 plays a key role in the development of specific neuronal subsets in the mouse cerebellum. Neural Dev. 6:25. doi: 10.1186/1749-8104-6-25

Chung, S.-H., Marzban, H., and Hawkes, R. (2009a). Compartmentation of the cerebellar nuclei of the mouse. Neuroscience 161, 123-138. doi: 10.1016/j. neuroscience.2009.03.037

Chung, S.-H., Sillitoe, R. V., Croci, L., Badaloni, A., Consalez, G., and Hawkes, R. (2009b). Purkinje cell phenotype restricts the distribution of unipolar brush cells. Neuroscience 164, 1496-1508. doi: 10.1016/j.neuroscience.2009. 09.080

Chung, S., Zhang, Y., Van Der Hoorn, F., and Hawkes, R. (2007). The anatomy of the cerebellar nuclei in the normal and scrambler mouse as revealed by the expression of the microtubule-associated protein kinesin light chain 3. Brain Res. 1140, 120-131. doi: 10.1016/j.brainres.2006.01.100

Consalez, G. G., and Hawkes, R. (2013). The compartmental restriction of cerebellar interneurons. Front. Neural Circuits 6:123. doi: 10.3389/fncir.2012. 00123

Cooper, J. A. (2013). Mechanisms of cell migration in the nervous system. J. Cell Biol. 202, 725-734. doi: 10.1083/jcb.201305021

D'Arcangelo, G., Miao, G. G., Chen, S. C., Soares, H. D., Morgan, J. I., and Curran, T. (1995). A protein related to extracellular matrix proteins deleted in the mouse mutant reeler. Nature 374, 719-723. doi: 10.1038/374719a0

Davies, J. (2013). Mechanisms of Morphogenesis. San Diego, CA: Academic Press.

De Zeeuw, C. I., and Hoogland, T. M. (2015). Reappraisal of Bergmann glial cells as modulators of cerebellar circuit function. Front. Cell. Neurosci. 9:246. doi: $10.3389 /$ fncel.2015.00246

Demkow, U., and Ploski, R. (2015). Clinical Applications for Next-Generation Sequencing. Cambridge, MA: Academic Press.

Deutsch, S. I., Burket, J. A., and Katz, E. (2010). Does subtle disturbance of neuronal migration contribute to schizophrenia and other neurodevelopmental disorders? potential genetic mechanisms with possible treatment implications. Eur. Neuropsychopharmacol. 20, 281-287. doi: 10.1016/j.euroneuro.2010. 02.005

Dey, J., Ditzler, S., Knoblaugh, S. E., Hatton, B. A., Schelter, J. M., Cleary, M. A., et al. (2012). A distinct smoothened mutation causes severe cerebellar developmental defects and medulloblastoma in a novel transgenic mouse model. Mol. Cell. Biol. 32, 4104-4115. doi: 10.1128/mcb.00862-12

Eiraku, M., Tohgo, A., Ono, K., Kaneko, M., Fujishima, K., Hirano, T., et al. (2005). DNER acts as a neuron-specific notch ligand during Bergmann glial development. Nat. Neurosci. 8, 873-880. doi: 10.1038/nn1492

Eisenman, L. M., Schalekamp, M. P., and Voogd, J. (1991). Development of the cerebellar cortical efferent projection: an in-vitro anterograde tracing study in rat brain slices. Brain Res. Dev. 60, 261-266. doi: 10.1016/0165-3806(91) 90055-n

Elsen, G. E., Juric-Sekhar, G., Daza, R. A., and Hevner, R. F. (2013). “Development of cerebellar nuclei," in Handbook of the Cerebellum and Cerebellar Disorders, eds M. Manto, D. Gruol, J. Schmahmann, N. Koibuchi and F. Rossi (Heidelberg: Springer), 179-205.

Englund, C., Kowalczyk, T., Daza, R. A., Dagan, A., Lau, C., Rose, M. F., et al. (2006). Unipolar brush cells of the cerebellum are produced in the rhombic lip and migrate through developing white matter. J. Neurosci. 26, 9184-9195. doi: 10.1523/jneurosci.1610-06.2006

Fatemi, S. H. (2005). Reelin glycoprotein: structure, biology and roles in health and disease. Mol. Psychiatry 10, 251-257. doi: 10.1038/sj.mp.4001613

Faust, P. L. (2003). Abnormal cerebellar histogenesis in PEX2 zellweger mice reflects multiple neuronal defects induced by peroxisome deficiency. J. Comp. Neurol. 461, 394-413. doi: 10.1002/cne.10699

Feng, Y., and Walsh, C. A. (2001). Protein-protein interactions, cytoskeletal regulation and neuronal migration. Nat. Rev. Neurosci. 2, 408-416. doi: $10.1038 / 35077559$

Fink, A. J., Englund, C., Daza, R. A., Pham, D., Lau, C., Nivison, M., et al. (2006). Development of the deep cerebellar nuclei: transcription factors and cell migration from the rhombic lip. J. Neurosci. 26, 3066-3076. doi: 10.1523/jneurosci.5203-05.2006

Flames, N., Long, J. E., Garratt, A. N., Fischer, T. M., Gassmann, M., Birchmeier, C., et al. (2004). Short-and long-range attraction of cortical GABAergic interneurons by neuregulin-1. Neuron 44, 251-261. doi: 10.1016/j. neuron.2004.09.028

Forster, E., Jossin, Y., Zhao, S., Chai, X., Frotscher, M., and Goffinet, A. M. (2006). Recent progress in understanding the role of reelin in radial neuronal migration, with specific emphasis on the dentate gyrus. Eur. J. Neurosci. 23, 901-909. doi: 10.1111/j.1460-9568.2006.04612.x

Fujita, H., Morita, N., Furuichi, T., and Sugihara, I. (2012). Clustered fine compartmentalization of the mouse embryonic cerebellar cortex and its rearrangement into the postnatal striped configuration. J. Neurosci. 32, 15688-15703. doi: 10.1523/jneurosci.1710-12.2012

Fukaya, M., Yamada, K., Nagashima, M., Tanaka, K., and Watanabe, M. (1999). Down-regulated expression of glutamate transporter GLAST in purkinje cell-associated astrocytes of reeler and weaver mutant cerebella. Neurosci. Res. 34, 165-175. doi: 10.1016/s0168-0102(99)00052-8

Gil-Sanz, C., Franco, S. J., Martinez-Garay, I., Espinosa, A., Harkins-Perry, S., and Müller, U. (2013). Cajal-Retzius cells instruct neuronal migration by coincidence signaling between secreted and contact-dependent guidance cues. Neuron 79, 461-477. doi: 10.1016/j.neuron.2013.06.040

Gleeson, J. G., Allen, K. M., Fox, J. W., Lamperti, E. D., Berkovic, S., Scheffer, I., et al. (1998). Doublecortin, a brain-specific gene mutated in human X-linked lissencephaly and double cortex syndrome, encodes a putative signaling protein. Cell 92, 63-72. doi: 10.1016/s0092-8674(00)80899-5

Gleeson, J. G., Lin, P. T., Flanagan, L. A., and Walsh, C. A. (1999). Doublecortin is a microtubule-associated protein and is expressed widely by migrating neurons. Neuron 23, 257-271. doi: 10.1016/s0896-6273(00)80778-3

Gleeson, J. G., and Walsh, C. A. (2000). Neuronal migration disorders: from genetic diseases to developmental mechanisms. Trends Neurosci. 23, 352-359. doi: 10.1016/s0166-2236(00)01607-6

Goffinet, A. (1983). The embryonic development of the cerebellum in normal and reeler mutant mice. Anat. Embryol. 168, 73-86. doi: 10.1007/bf003 05400

Goldowitz, D., Cushing, R. C., Laywell, E., D’Arcangelo, G., Sheldon, M., Sweet, H. O., et al. (1997). Cerebellar disorganization characteristic of reeler in scrambler mutant mice despite presence of reelin. J. Neurosci. 17, 8767-8777. doi: 10.1523/jneurosci.17-22-08767.1997

Govek, E. E., Hatten, M. E., and Van Aelst, L. (2011). The role of rho GTPase proteins in CNS neuronal migration. Dev. Neurobiol. 71, 528-553. doi: 10.1002/dneu.20850

Greene, M., Lai, Y., Pajcini, K., Bailis, W., Pear, W. S., and Lancaster, E. (2016). Delta/notch-like EGF-related receptor (DNER) is not a notch ligand. PLoS One 11:e0161157. doi: 10.1371/journal.pone.0161157

Guerrini, R., and Parrini, E. (2010). Neuronal migration disorders. Neurobiol. Dis. 38, 154-166. doi: 10.1016/j.nbd.2009.02.008

Hadj-Sahraoui, N., Frederic, F., Zanjani, H., Herrup, K., Delhaye-Bouchaud, N., and Mariani, J. (1997). Purkinje cell loss in heterozygous staggerer mutant mice during aging. Dev. Brain Res. 98, 1-8. doi: 10.1016/s0165-3806(96)00153-8

Hagan, N., and Zervas, M. (2012). Wnt1 expression temporally allocates upper rhombic lip progenitors and defines their terminal cell fate in the cerebellum. Mol. Cell. Neurosci. 49, 217-229. doi: 10.1016/j.mcn.2011.11.008

Hagihara, K., Zhang, E. E., Ke, Y. H., Liu, G., Liu, J. J., Rao, Y., et al. (2009). Shp2 acts downstream of SDF-1 $\alpha /$ CXCR4 in guiding granule cell migration during cerebellar development. Dev. Biol. 334, 276-284. doi: 10.1016/j.ydbio. 2009.07.029

Hallonet, M., and Alvarado-Mallart, R.-M. (1996). The chick/quail chimeric system: a model for early cerebellar development. Perspect. Dev. Neurobiol. 5 , 17-31.

Hashimoto, M., and Mikoshiba, K. (2003). Mediolateral compartmentalization of the cerebellum is determined on the "birth date" of Purkinje cells. J. Neurosci. 23, 11342-11351. doi: 10.1523/jneurosci.23-36-11342.2003

Hashimoto, M., and Mikoshiba, K. (2004). Neuronal birthdate-specific gene transfer with adenoviral vectors. J. Neurosci. 24, 286-296. doi: 10.1523/jneurosci.2529-03.2004

Hatten, M. E. (1990). Riding the glial monorail: a common mechanism for glial-guided neuronal migration in different regions of the developing 
mammalian brain. Trends Neurosci. 13, 179-184. doi: 10.1016/0166-2236(90) 90044-b

Hatten, M. E. (1999). Central nervous system neuronal migration. Annu. Rev. Neurosci. 22, 511-539. doi: 10.1146/annurev.neuro.22.1.511

Hatten, M. E., and Heintz, N. (1995). Mechanisms of neural patterning and specification in the development cerebellum. Annu. Rev. Neurosci. 18, 385-408. doi: 10.1146/annurev.ne.18.030195.002125

Hevner, R. F., Hodge, R. D., Daza, R. A., and Englund, C. (2006). Transcription factors in glutamatergic neurogenesis: conserved programs in neocortex, cerebellum and adult hippocampus. Neurosci. Res. 55, 223-233. doi: 10.1016/j. neures.2006.03.004

Hiraoka, Y., Komine, O., Nagaoka, M., Bai, N., Hozumi, K., and Tanaka, K. (2013). Delta-like 1 regulates Bergmann glial monolayer formation during cerebellar development. Mol. Brain 6:25. doi: 10.1186/1756-6606-6-25

Hoshino, M., Nakamura, S., Mori, K., Kawauchi, T., Terao, M., Nishimura, Y. V., et al. (2005). Ptfla, a bHLH transcriptional gene, defines GABAergic neuronal fates in cerebellum. Neuron 47, 201-213. doi: 10.1016/j.neuron.2005.06.007

Howell, B. W., Hawkes, R., Soriano, P., and Cooper, J. A. (1997). Neuronal position in the developing brain is regulated by mouse disabled-1. Nature 389, 733-737. doi: $10.1038 / 39607$

Huang, G.-J., Edwards, A., Tsai, C.-Y., Lee, Y.-S., Peng, L., Era, T., et al. (2014). Ectopic cerebellar cell migration causes maldevelopment of Purkinje cells and abnormal motor behaviour in Cxcr4 null mice. PLoS one 9:e86471. doi: 10.1371/journal.pone.0086471

Inada, H., Watanabe, M., Uchida, T., Ishibashi, H., Wake, H., Nemoto, T., et al. (2011). GABA regulates the multidirectional tangential migration of GABAergic interneurons in living neonatal mice. PLoS One 6:e27048. doi: 10.1371 /journal.pone.0027048

Jensen, P., Zoghbi, H. Y., and Goldowitz, D. (2002). Dissection of the cellular and molecular events that position cerebellar Purkinje cells: a study of the math1 null-mutant mouse. J. Neurosci. 22, 8110-8116. doi: 10.1523/jneurosci.22-1808110.2002

Kawaji, K., Umeshima, H., Eiraku, M., Hirano, T., and Kengaku, M. (2004). Dual phases of migration of cerebellar granule cells guided by axonal and dendritic leading processes. Mol. Cell. Neurosci. 25, 228-240. doi: 10.1016/j.mcn.2003. 10.006

Kawauchi, D., Taniguchi, H., Watanabe, H., Saito, T., and Murakami, F. (2006). Direct visualization of nucleogenesis by precerebellar neurons: involvement of ventricle-directed, radial fibre-associated migration. Development 133, 1113-1123. doi: 10.1242/dev.02283

Kim, J. Y., Marzban, H., Chung, S. H., Watanabe, M., Eisenman, L. M., and Hawkes, R. (2009). Purkinje cell compartmentation of the cerebellum of microchiropteran bats. J. Comp. Neurol. 517, 193-209. doi: 10.1002/cne.22147

Kim, E., Wang, Y., Kim, S. J., Bornhorst, M., Jecrois, E. S., Anthony, T. E., et al. (2014). Transient inhibition of the ERK pathway prevents cerebellar developmental defects and improves long-term motor functions in murine models of neurofibromatosis type 1. Elife 3:3:e05151. doi: 10.7554/elife.05151

Komine, O., Nagaoka, M., Watase, K., Gutmann, D. H., Tanigaki, K., Honjo, T., et al. (2007). The monolayer formation of Bergmann glial cells is regulated by Notch/RBP-J signaling. Dev. Biol. 311, 238-250. doi: 10.1016/j.ydbio.2007. 08.042

Komuro, Y., Galas, L., Lebon, A., Raoult, E., Fahrion, J. K., Tilot, A., et al. (2015). The role of calcium and cyclic nucleotide signaling in cerebellar granule cell migration under normal and pathological conditions. Dev. Neurobiol. 75, 369-387. doi: 10.1002/dneu.22219

Komuro, H., and Yacubova, E. (2003). Recent advances in cerebellar granule cell migration. Cell. Mol. Life Sci. 60, 1084-1098. doi: 10.1007/s00018-003-2248-z

Komuro, H., Yacubova, E., Yacubova, E., and Rakic, P. (2001). Mode and tempo of tangential cell migration in the cerebellar external granular layer. J. Neurosci. 21, 527-540. doi: 10.1523/jneurosci.21-02-00527.2001

Krause, M., and Gautreau, A. (2014). Steering cell migration: lamellipodium dynamics and the regulation of directional persistence. Nat. Rev. Mol. Cell Biol. 15, 577-590. doi: 10.1038/nrm3861

Kuo, G., Arnaud, L., Kronstad-O'Brien, P., and Cooper, J. A. (2005). Absence of Fyn and Src causes a reeler-like phenotype. J. Neurosci. 25, 8578-8586. doi: 10.1523/jneurosci.1656-05.2005

Kurosaka, S., and Kashina, A. (2008). Cell biology of embryonic migration. Birth Defects Res. C Embryo Today 84, 102-122. doi: 10.1002/bdrc.20125
Larouche, M., and Hawkes, R. (2006). From clusters to stripes: the developmental origins of adult cerebellar compartmentation. Cerebellum 5, 77-88. doi: 10.1080/14734220600804668

Leto, K., Arancillo, M., Becker, E. B., Buffo, A., Chiang, C., Ding, B., et al. (2016). Consensus paper: cerebellar development. Cerebellum 15, 789-828. doi: 10.1007/s12311-015-0724-2

Leung, A. W., and Li, J. Y. H. (2018). The molecular pathway regulating bergmann glia and folia generation in the cerebellum. Cerebellum 17, 42-48. doi: 10.1007/s12311-017-0904-3

Lewis, P. M., Gritli-Linde, A., Smeyne, R., Kottmann, A., and McMahon, A. P. (2004). Sonic hedgehog signaling is required for expansion of granule neuron precursors and patterning of the mouse cerebellum. Dev. Biol. 270, 393-410. doi: 10.1016/j.ydbio.2004.03.007

Li, K., Leung, A. W., Guo, Q., Yang, W., and Li, J. Y. (2014). Shp2-dependent ERK signaling is essential for induction of Bergmann glia and foliation of the cerebellum. J. Neurosci. 34, 922-931. doi: 10.1523/jneurosci.3476-13.2014

Müller, F., and O'Rahilly, R. (1990). The human brain at stages 18-20, including the choroid plexuses and the amygdaloid and septal nuclei. Anat. Embryol. 182, 285-306. doi: 10.1007/bf00185521

Ma, Q., Jones, D., Borghesani, P. R., Segal, R. A., Nagasawa, T., Kishimoto, T., et al. (1998). Impaired B-lymphopoiesis, myelopoiesis and derailed cerebellar neuron migration in CXCR4-and SDF-1-deficient mice. Proc. Natl. Acad. Sci. U S A 95, 9448-9453. doi: 10.1073/pnas.95.16.9448

Machold, R., and Fishell, G. (2005). Math1 is expressed in temporally discrete pools of cerebellar rhombic-lip neural progenitors. Neuron 48, 17-24. doi: 10.1016/j.neuron.2005.08.028

Maitre, J. L., and Heisenberg, C. P. (2013). Three functions of cadherins in cell adhesion. Curr. Biol. 23, R626-R633. doi: 10.1016/j.cub.2013.06.019

Malek, R., Matta, J., Taylor, N., Perry, M. E., and Mendrysa, S. M. (2011). The p53 inhibitor MDM2 facilitates sonic hedgehog-mediated tumorigenesis and influences cerebellar foliation. PLoS One 6:e17884. doi: 10.1371/journal.pone. 0017884

Mannan, A. U., Roussa, E., Kraus, C., Rickmann, M., Maenner, J., Nayernia, K., et al. (2004). Mutation in the gene encoding lysosomal acid phosphatase (Acp2) causes cerebellum and skin malformation in mouse. Neurogenetics 5, 229-238. doi: 10.1007/s10048-004-0197-9

Manohar, S., Paolone, N. A., Bleichfeld, M., Hayes, S. H., Salvi, R. J., and Baizer, J. S. (2012). Expression of doublecortin, a neuronal migration protein, in unipolar brush cells of the vestibulocerebellum and dorsal cochlear nucleus of the adult rat. Neuroscience 202, 169-183. doi: 10.1016/j.neuroscience.2011.12.013

Manto, M., Gruol, D. L., Schmahmann, J. D., Koibuchi, N., and Rossi, F. (2013). Handbook of the Cerebellum and Cerebellar Disorders. (Vol. 4), Netherlands: Springer.

Maricich, S. M., and Herrup, K. (1999). Pax-2 expression defines a subset of GABAergic interneurons and their precursors in the developing murine cerebellum. J. Neurobiol. 41, 281-294. doi: 10.1002/(sici)10974695(19991105)41:2<281::aid-neu10>3.0.co;2-5

Marín, O., and Rubenstein, J. L. (2001). A long, remarkable journey: tangential migration in the telencephalon. Nat. Rev. Neurosci. 2, 780-790. doi: $10.1038 / 35097509$

Marín, O., Valiente, M., Ge, X., and Tsai, L.-H. (2010). Guiding neuronal cell migrations. Cold Spring Harb. Perspect. Biol. 2:a001834. doi: 10.1101/cshperspect.a001834

Marino, S., Hoogervoorst, D., Brandner, S., and Berns, A. (2003). Rb and p107 are required for normal cerebellar development and granule cell survival but not for Purkinje cell persistence. Development 130, 3359-3368. doi: 10.1242/dev. 00553

Martini, F. J., and Valdeolmillos, M. (2010). Actomyosin contraction at the cell rear drives nuclear translocation in migrating cortical interneurons. J. Neurosci. 30, 8660-8670. doi: 10.1523/jneurosci.1962-10.2010

Marzban, H., Chung, S., Watanabe, M., and Hawkes, R. (2007). Phospholipase CB4 expression reveals the continuity of cerebellar topography through development. J. Comp. Neurol. 502, 857-871. doi: 10.1002/cne.21352

Marzban, H., Del Bigio, M. R., Alizadeh, J., Ghavami, S., Zachariah, R. M., and Rastegar, M. (2015). Cellular commitment in the developing cerebellum. Front. Cell. Neurosci. 8:450. doi: 10.3389/fncel.2014.00450

Marzban, H., and Hawkes, R. (2011). On the architecture of the posterior zone of the cerebellum. Cerebellum 10, 422-434. doi: 10.1007/s12311-010-0208-3 
Marzban, H., Kim, C. T., Doorn, D., Chung, S. H., and Hawkes, R. (2008). A novel transverse expression domain in the mouse cerebellum revealed by a neurofilament-associated antigen. Neuroscience 153, 1190-1201. doi: 10.1016/j. neuroscience.2008.02.036

Matsuki, T., Chen, J., and Howell, B. W. (2013). Acute inactivation of the serine-threonine kinase Stk25 disrupts neuronal migration. Neural Dev. 8:21. doi: 10.1186/1749-8104-8-21

Mattila, P. K., and Lappalainen, P. (2008). Filopodia: molecular architecture and cellular functions. Nat. Rev. Mol. Cell Biol. 9, 446-454. doi: 10.1038/nrm2406

Mayer, H., Duit, S., Hauser, C., Schneider, W. J., and Nimpf, J. (2006). Reconstitution of the reelin signaling pathway in fibroblasts demonstrates that Dab1 phosphorylation is independent of receptor localization in lipid rafts. Mol. Cell. Biol. 26, 19-27. doi: 10.1128/mcb.26.1.19-27.2006

Minaki, Y., Nakatani, T., Mizuhara, E., Inoue, T., and Ono, Y. (2008). Identification of a novel transcriptional corepressor, Corl2, as a cerebellar Purkinje cell-selective marker. Gene Expr. Patterns 8, 418-423. doi: 10.1016/j. gep.2008.04.004

Miyata, T., Maeda, T., and Lee, J. E. (1999). NeuroD is required for differentiation of the granule cells in the cerebellum and hippocampus. Genes Dev. 13, 1647-1652. doi: 10.1101/gad.13.13.1647

Miyata, T., Ono, Y., Okamoto, M., Masaoka, M., Sakakibara, A., Kawaguchi, A., et al. (2010). Migration, early axonogenesis and reelin-dependent layer-forming behavior of early/posterior-born Purkinje cells in the developing mouse lateral cerebellum. Neural Dev. 5:23. doi: 10.1186/1749-8104-5-23

Morales, D., and Hatten, M. E. (2006). Molecular markers of neuronal progenitors in the embryonic cerebellar anlage. J. Neurosci. 26, 12226-12236. doi: 10.1523/JNEUROSCI.3493-06.2006

Nadarajah, B., Alifragis, P., Wong, R. O., and Parnavelas, J. G. (2003). Neuronal migration in the developing cerebral cortex: observations based on real-time imaging. Cereb. Cortex 13, 607-611. doi: 10.1093/cercor/13.6.607

Nadarajah, B., Brunstrom, J. E., Grutzendler, J., Wong, R. O., and Pearlman, A. L. (2001). Two modes of radial migration in early development of the cerebral cortex. Nat. Neurosci. 4, 143-150. doi: 10.1038/83967

Nadarajah, B., and Parnavelas, J. G. (2002). Modes of neuronal migration in the developing cerebral cortex. Nat. Rev. Neurosci. 3, 423-432. doi: 10.1038/ nrn845

Nguyen, L., and Hippenmeyer, S. (2013). Cellular and Molecular Control of Neuronal Migration. Dordrecht: Springer Science \& Business Media.

Nichols, D. H., and Bruce, L. L. (2006). Migratory routes and fates of cells transcribing the Wnt-1 gene in the murine hindbrain. Dev. Dyn. 235, 285-300. doi: $10.1002 /$ dvdy.20611

Nóbrega-Pereira, S., and Marin, O. (2009). Transcriptional control of neuronal migration in the developing mouse brain. Cereb. Cortex 19, i107-i113. doi: 10.1093/cercor/bhp044

O’Hearn, E., and Molliver, M. E. (1997). The olivocerebellar projection mediates ibogaine-induced degeneration of Purkinje cells: a model of indirect, transsynaptic excitotoxicity. J. Neurosci. 17, 8828-8841. doi: 10.1523/jneurosci.1722-08828.1997

Paolone, N., Manohar, S., Hayes, S. H., Wong, K. M., Salvi, R. J., and Baizer, J. S. (2014). Dissociation of doublecortin expression and neurogenesis in unipolar brush cells in the vestibulocerebellum and dorsal cochlear nucleus of the adult rat. Neuroscience 265, 323-331. doi: 10.1016/j.neuroscience.2014.01.026

Peng, C., Ye, J., Yan, S., Kong, S., Shen, Y., Li, C., et al. (2012). Ablation of vacuole protein sorting 18 (Vps18) gene leads to neurodegeneration and impaired neuronal migration by disrupting multiple vesicle transport pathways to lysosomes. J. Biol. Chem. 287, 32861-32873. doi: 10.1074/jbc.M112. 384305

Pijpers, A., Apps, R., Pardoe, J., Voogd, J., and Ruigrok, T. J. (2006). Precise spatial relationships between mossy fibers and climbing fibers in rat cerebellar cortical zones. J. Neurosci. 26, 12067-12080. doi: 10.1523/JNEUROSCI.2905 $-06.2006$

Powell, E. M., Mars, W. M., and Levitt, P. (2001). Hepatocyte growth factor/scatter factor is a motogen for interneurons migrating from the ventral to dorsal telencephalon. Neuron 30, 79-89. doi: 10.1016/s0896-6273(01) 00264-1

Qin, R., Cao, S., Lyu, T., Qi, C., Zhang, W., and Wang, Y. (2017). CDYL deficiency disrupts neuronal migration and increases susceptibility to epilepsy. Cell Rep. 18, 380-390. doi: 10.1016/j.celrep.2016.12.043
Rahimi-Balaei, M., Afsharinezhad, P., Bailey, K., Buchok, M., Yeganeh, B., and Marzban, H. (2015). Embryonic stages in cerebellar afferent development. Cerebellum Ataxias 2:7. doi: 10.1186/s40673-015-0026-y

Rahimi-Balaei, M., Jiao, X., Ashtari, N., Afsharinezhad, P., Ghavami, S., and Marzban, H. (2016). Cerebellar expression of the neurotrophin receptor p75 in naked-ataxia mutant mouse. Int. J. Mol. Sci. 17:115. doi: 10.3390/ijms170 10115

Rahimi-Balaei, M., Jiao, X., Shabanipour, S., Dixit, R., Schuurmans, C., and Marzban, H. (2018). Zebrin II is ectopically expressed in microglia in the cerebellum of neurogenin 2 null mice. Cerebellum doi: 10.1007/s12311-0180944-3 [Epub ahead of print].

Rakic, P. (1971). Neuron-glia relationship during granule cell migration in developing cerebellar cortex. a golgi and electonmicroscopic study in macacus rhesus. J. Comp. Neurol. 141, 283-312. doi: 10.1002/cne.901410303

Rakic, P. (1990). Principles of neural cell migration. Experientia 46, 882-891. doi: $10.1007 / \mathrm{bf} 01939380$

Rakic, P., and Sidman, R. L. (1970). Histogenesis of cortical layers in human cerebellum, particularly the lamina dissecans. J. Comp. Neurol. 139, 473-500. doi: 10.1002/cne.901390407

Rakic, P., and Sidman, R. (1973). Weaver mutant mouse cerebellum: defective neuronal migration secondary to abnormality of Bergmann glia. Proc. Natl. Acad. Sci. U S A 70, 240-244. doi: 10.1073/pnas.70.1.240

Reddy, S. S., Connor, T. E., Weeber, E. J., and Rebeck, W. (2011). Similarities and differences in structure, expression and functions of VLDLR and ApoER2. Mol. Neurodegener. 6:30. doi: 10.1186/1750-1326-6-30

Reeber, S. L., Arancillo, M., and Sillitoe, R. V. (2018). Bergmann glia are patterned into topographic molecular zones in the developing and adult mouse cerebellum. Cerebellum 17, 392-403. doi: 10.1007/s12311-014 $-0571-6$

Reeber, S. L., Loeschel, C. A., Franklin, A., and Sillitoe, R. V. (2013). Establishment of topographic circuit zones in the cerebellum of scrambler mutant mice. Front. Neural Circuits 7:122. doi: 10.3389/fncir.2013.00122

Sanada, K., Gupta, A., and Tsai, L. H. (2004). Disabled-1-regulated adhesion of migrating neurons to radial glial fiber contributes to neuronal positioning during early corticogenesis. Neuron 42, 197-211. doi: 10.1016/S08966273(04)00222-3

Schilling, K. (2018). Moving into shape: cell migration during the development and histogenesis of the cerebellum. Histochem. Cell Biol. doi: 10.1007/s00418 018-1677-6 [Epub ahead of print].

Schofield, P. N., Hoehndorf, R., and Gkoutos, G. V. (2012). Mouse genetic and phenotypic resources for human genetics. Hum. Mutat. 33, 826-836. doi: 10.1002/humu.22077

Sheldon, M., Rice, D. S., D’Arcangelo, G., Yoneshima, H., Nakajima, K., Mikoshiba, K., et al. (1997). Scrambler and yotari disrupt the disabled gene and produce a reeler-like phenotype in mice. Nature 389, 730-733. doi: $10.1038 / 39601$

Sillitoe, R. V. (2016). Mossy fibers terminate directly within purkinje cell zones during mouse development. Cerebellum 15, 14-17. doi: 10.1007/s12311-0150712-6

Sillitoe, R. V., Gopal, N., and Joyner, A. L. (2009). Embryonic origins of ZebrinII parasagittal stripes and establishment of topographic Purkinje cell projections. Neuroscience 162, 574-588. doi: 10.1016/j.neuroscience.2008.12.025

Sillitoe, R. V., Marzban, H., Larouche, M., Zahedi, S., Affanni, J., and Hawkes, R. (2005). Conservation of the architecture of the anterior lobe vermis of the cerebellum across mammalian species. Prog. Brain Res. 148, 283-297. doi: 10.1016/s0079-6123(04)48022-4

Smeyne, R. J., and Goldowitz, D. (1989). Development and death of external granular layer cells in the weaver mouse cerebellum: a quantitative study. J. Neurosci. 9, 1608-1620. doi: 10.1523/JNEUROSCI.09-05-01608.1989

Solecki, D. J., Trivedi, N., Govek, E.-E., Kerekes, R. A., Gleason, S. S., and Hatten, M. E. (2009). Myosin II motors and F-actin dynamics drive the coordinated movement of the centrosome and soma during CNS glialguided neuronal migration. Neuron 63, 63-80. doi: 10.1016/j.neuron.2009. 05.028

Sotelo, C. (2017). "Cerebellar transplantation: a potential model to study repair and development of neurons and circuits in the cerebellum," in Development of the Cerebellum from Molecular Aspects to Diseases, ed. H. Marzban (Cham: Springer), 465-493. doi: 10.1007/978-3-319-59749-2_22 
Sotelo, C., and Dusart, I. (2009). Intrinsic versus extrinsic determinants during the development of Purkinje cell dendrites. Neuroscience 162, 589-600. doi: 10.1016/j.neuroscience.2008.12.035

Stenman, J., Toresson, H., and Campbell, K. (2003). Identification of two distinct progenitor populations in the lateral ganglionic eminence: implications for striatal and olfactory bulb neurogenesis. J. Neurosci. 23, 167-174. doi: 10.1523/JNEUROSCI.23-01-00167.2003

Stoykova, A., and Gruss, P. (1994). Roles of Pax-genes in developing and adult brain as suggested by expression patterns. J. Neurosci. 14, 1395-1412. doi: 10.1523/jneurosci.14-03-01395.1994

Sudarov, A., and Joyner, A. L. (2007). Cerebellum morphogenesis: the foliation pattern is orchestrated by multi-cellular anchoring centers. Neural Dev. 2:26. doi: 10.1186/1749-8104-2-26

Sugihara, I. (2011). Compartmentalization of the deep cerebellar nuclei based on afferent projections and aldolase C expression. Cerebellum 10, 449-463. doi: 10.1007/s12311-010-0226-1

Sugihara, I., and Quy, P. N. (2007). Identification of aldolase C compartments in the mouse cerebellar cortex by olivocerebellar labeling. J. Comp. Neurol. 500, 1076-1092. doi: 10.1002/cne.21219

Sugihara, I., and Shinoda, Y. (2004). Molecular, topographic, and functional organization of the cerebellar cortex: a study with combined aldolase $\mathrm{C}$ and olivocerebellar labeling. J. Neurosci. 24, 8771-8785. doi: 10.1523/jneurosci. 1961-04.2004

Sugihara, I., and Shinoda, Y. (2007). Molecular, topographic, and functional organization of the cerebellar nuclei: analysis by three-dimensional mapping of the olivonuclear projection and aldolase C labeling. J. Neurosci. 27, 9696-9710. doi: 10.1523/jneurosci.1579-07.2007

Tabata, H., and Nakajima, K. (2003). Multipolar migration: the third mode of radial neuronal migration in the developing cerebral cortex. J. Neurosci. 23, 9996-10001. doi: 10.1523/jneurosci.23-31-09996.2003

Takei, Y., Teng, J., Harada, A., and Hirokawa, N. (2000). Defects in axonal elongation and neuronal migration in mice with disrupted tau and maplb genes. J. Cell Biol. 150, 989-1000. doi: 10.1083/jcb.150.5.989

Tanaka, T., Serneo, F. F., Higgins, C., Gambello, M. J., Wynshaw-Boris, A., and Gleeson, J. G. (2004). Lis1 and doublecortin function with dynein to mediate coupling of the nucleus to the centrosome in neuronal migration. J. Cell Biol. 165, 709-721. doi: 10.1083/jcb.200309025

Tanaka, D. H., Yanagida, M., Zhu, Y., Mikami, S., Nagasawa, T., and Miyazaki, J. (2009). Random walk behavior of migrating cortical interneurons in the marginal zone: time-lapse analysis in flat-mount cortex. J. Neurosci. 29, 1300-1311. doi: 10.1523/jneurosci.5446-08.2009

Tissir, F., Wang, C.-E., and Goffinet, A. M. (2004). Expression of the chemokine receptor Cxcr4 mRNA during mouse brain development. Dev. Brain Res. 149, 63-71. doi: 10.1016/j.devbrainres.2004.01.002

Tohgo, A., Eiraku, M., Miyazaki, T., Miura, E., Kawaguchi, S.-Y., Nishi, M., et al. (2006). Impaired cerebellar functions in mutant mice lacking DNER. Mol. Cell. Neurosci. 31, 326-333. doi: 10.1016/j.mcn.2005.10.003

Trommsdorff, M., Gotthardt, M., Hiesberger, T., Shelton, J., Stockinger, W., Nimpf, J., et al. (1999). Reeler/disabled-like disruption of neuronal migration in knockout mice lacking the VLDL receptor and ApoE receptor 2. Cell 97, 689-701. doi: 10.1016/s0092-8674(00)80782-5

Tsai, L.-H., and Gleeson, J. G. (2005). Nucleokinesis in neuronal migration. Neuron 46, 383-388. doi: 10.1016/j.neuron.2005.04.013

Tsai, H.-H., Niu, J., Munji, R., Davalos, D., Chang, J., Zhang, H., et al. (2016). Oligodendrocyte precursors migrate along vasculature in the developing nervous system. Science 351, 379-384. doi: 10.1126/science.aad3839

Voogd, J. (1967). Comparative aspects of the structure and fibre connexions of the mammalian cerebellum. Prog. Brain Res. 25, 94-134. doi: 10.1016/s00796123(08)60963-2

Wallace, V. A. (1999). Purkinje-cell-derived sonic hedgehog regulates granule neuron precursor cell proliferation in the developing mouse cerebellum. Curr. Biol. 9, 445-448. doi: 10.1016/s0960-9822(99)80195-x
Wang, V. Y., and Zoghbi, H. Y. (2001). Genetic regulation of cerebellar development. Nat. Rev. Neurosci. 2, 484-491. doi: 10.1038/35081558

Wefers, A. K., Haberlandt, C., Surchev, L., Steinhäuser, C., Jabs, R., and Schilling, K. (2018). Migration of interneuron precursors in the nascent cerebellar cortex. Cerebellum 17, 62-71. doi: 10.1007/s12311-017 $-0900-7$

Weisheit, G., Gliem, M., Endl, E., Pfeffer, P. L., Busslinger, M., and Schilling, K. (2006). Postnatal development of the murine cerebellar cortex: formation and early dispersal of basket, stellate and golgi neurons. Eur. J. Neurosci. 24, 466-478. doi: 10.1111/j.1460-9568.2006.04915.x

White, J. J., and Sillitoe, R. V. (2013). Postnatal development of cerebellar zones revealed by neurofilament heavy chain protein expression. Front. Neuroanat. 7:9. doi: 10.3389/fnana.2013.00009

Wynshaw-Boris, A., and Gambello, M. J. (2001). LIS1 and dynein motor function in neuronal migration and development. Genes Dev. 15, 639-651. doi: 10.1101/gad. 886801

Yacubova, E., and Komuro, H. (2003). Cellular and molecular mechanisms of cerebellar granule cell migration. Cell Biochem. Biophys. 37, 213-234. doi: 10.1385/cbb:37:3:213

Yamada, K., Fukaya, M., Shibata, T., Kurihara, H., Tanaka, K., Inoue, Y., et al. (2000). Dynamic transformation of Bergmann glial fibers proceeds in correlation with dendritic outgrowth and synapse formation of cerebellar Purkinje cells. J. Comp. Neurol. 418, 106-120. doi: 10.1002/(sici)10969861(20000228)418:1<106::aid-cne8>3.3.co;2-e

Yamada, K., and Watanabe, M. (2002). Cytodifferentiation of Bergmann glia and its relationship with Purkinje cells. Anat. Sci. Int. 77, 94-108. doi: 10.1046/j. 0022-7722.2002.00021.x

Yamanaka, H., Yanagawa, Y., and Obata, K. (2004). Development of stellate and basket cells and their apoptosis in mouse cerebellar cortex. Neurosci. Res. 50, 13-22. doi: 10.1016/j.neures.2004.06.008

Yee, K. T., Simon, H. H., Tessier-Lavigne, M., and O’Leary, D. D. (1999). Extension of long leading processes and neuronal migration in the mammalian brain directed by the chemoattractant netrin-1. Neuron 24, 607-622. doi: 10.1016/s0896-6273(00)81116-2

Yuasa, S. (1996). Bergmann glial development in the mouse cerebellum as revealed by tenascin expression. Anat. Embryol. 194, 223-234. doi: 10.1007/bf00187133

Yuasa, S., Kawamura, K., Kuwano, R., and Ono, K. (1996). Neuronglia interrelations during migration of Purkinje cells in the mouse embryonic cerebellum. Int. J. Dev. Neurosci. 14, 429-438. doi: 10.1016/07365748(96)00021-4

Yuasa, S., Kitoh, J., Oda, S.-I., and Kawamura, K. (1993). Obstructed migration of Purkinje cells in the developing cerebellum of the reeler mutant mouse. Anat. Embryol. 188, 317-329. doi: 10.1007/bf00185941

Yue, Q., Groszer, M., Gil, J. S., Berk, A. J., Messing, A., Wu, H., et al. (2005). PTEN deletion in Bergmann glia leads to premature differentiation and affects laminar organization. Development 132, 3281-3291. doi: 10.1242/dev. 01891

Zhang, L., and Goldman, J. E. (1996). Generation of cerebellar interneurons from dividing progenitors in white matter. Neuron 16, 47-54. doi: 10.1016/s08966273(00)80022-7

Conflict of Interest Statement: The authors declare that the research was conducted in the absence of any commercial or financial relationships that could be construed as a potential conflict of interest.

Copyright (C) 2018 Rahimi-Balaei, Bergen, Kong and Marzban. This is an open-access article distributed under the terms of the Creative Commons Attribution License (CC BY). The use, distribution or reproduction in other forums is permitted, provided the original author(s) and the copyright owner(s) are credited and that the original publication in this journal is cited, in accordance with accepted academic practice. No use, distribution or reproduction is permitted which does not comply with these terms. 